This item was submitted to Loughborough's Research Repository by the author.

Items in Figshare are protected by copyright, with all rights reserved, unless otherwise indicated.

\title{
Remote community integrated energy system optimization including building enclosure improvements and quantitative energy trilemma metrics
}

\section{PLEASE CITE THE PUBLISHED VERSION}

https://doi.org/10.1016/j.apenergy.2020.115017

\section{PUBLISHER}

Elsevier

VERSION

AM (Accepted Manuscript)

\section{PUBLISHER STATEMENT}

This paper was accepted for publication in the journal Applied Energy and the definitive published version is available at https://doi.org/10.1016/j.apenergy.2020.115017.

LICENCE

CC BY-NC-ND 4.0

\section{REPOSITORY RECORD}

Quitoras, Marvin, Pietro Campana, Paul Rowley, and Curran Crawford. 2020. "Remote Community Integrated Energy System Optimization Including Building Enclosure Improvements and Quantitative Energy Trilemma Metrics". Loughborough University. https://hdl.handle.net/2134/12236801.v1. 


\title{
Remote community integrated energy system optimization including building enclosure improvements and quantitative energy trilemma metrics
}

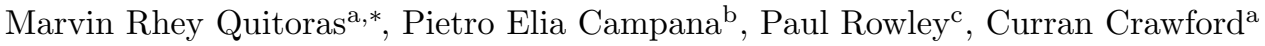 \\ ${ }^{a}$ Department of Mechanical Engineering, University of Victoria, \\ PO Box 3055 STN CSC, Victoria, BC V8W 2Y2, Canada \\ ${ }^{b}$ School of Business, Society \& Engineering, Mälardalen University, \\ Box 883, SE-72123 Västerås, Sweden \\ ${ }^{c}$ Center for Renewable Energy Systems Technology (CREST), School of Electronic, Electrical \& Systems \\ Engineering, Loughborough University, Leics. LE11 3TU, UK
}

\begin{abstract}
Design strategies for sustainable energy systems in remote communities require holistic approaches, as policy, technological development and complex energy systems operation are inherently intertwined. The present work takes a multi-domain perspective in which various energy solution philosophies co-exist. In particular, a multi-objective energy system model has been developed to determine the optimal configuration of integrated electrical and thermal energy systems for Sachs Harbour, the Northernmost community in the Northwest Territories of Canada. From the four scenarios implemented in the model, the Pareto front curves show that the fuel consumption can vary from $0-700,000 \mathrm{~L} / \mathrm{yr}$ while the cost of energy is in the range of $0.5-2.7 \mathrm{CND} \$ / \mathrm{kWh}$. Further, a comparative dynamic simulation has been carried out to analyze the impacts of using electric baseboard heaters versus air-source heat pumps. The results indicate that load fluctuations caused by the variations of the heat pumps' coefficients of performance negatively impact the operation of the energy system. These demand fluctuations result in a larger battery storage requirement, along with an increase in overall energy system costs. Building enclosure improvements alone were found to reduce space heating loads by up to $40 \%$. Finally, nine solutions of interest from the Pareto front were quantified and tested in the energy trilemma index model. From the multiple viable configurations, the proposed solution was estimated to have a weighted average trilemma score of 73.3. Overall, the use of such innovative modeling approaches in real-world applications can support policy makers to make informed decisions in balancing trade-offs from various energy solution viewpoints.
\end{abstract}

\section{Highlights}

- A novel holistic energy solution in accelerating energy transition is proposed.

- Heating load variations result in increased battery storage and system cost.

- Effective building insulation reduces heat load by about $40 \%$.

\footnotetext{
*Corresponding author

Email address: mdquitoras@uvic.ca (Marvin Rhey Quitoras)
} 
- A high performance building enables resilient energy system design.

- The energy trilemma index model can capture multiple decision makers' viewpoints.

Keywords: Energy system optimization; Air-source heat pump; Integrated energy system; Energy trilemma; Fuel poverty; Building enclosure

\section{Introduction}

The diversity of Arctic jurisdictions, spanning unique geographical locations from central municipalities to very isolated communities, and the predominant reliance upon obsolete diesel infrastructure play pivotal roles in the energy situation of Canada's North ${ }^{1}$ today [1]. Arctic communities have a critical dependence on energy services - heating, transportation, and electricity - for their safety, sustainability, and economic growth [2]. For decades, fossil fuels (mostly diesel) have been the primary source of energy in the territories of Canada as they are not connected to the North American electricity or natural gas grids. This situation exposes the Indigenous peoples and other Canadians living in the North to high energy costs and environmental vulnerabilities which is exacerbated by rapid ongoing climate changes in the region. Also, traditional transportation modes including winter roads are now increasingly unreliable because of the rising Arctic temperatures which impact access to reliable fuel sources. As a result, energy prices for households in Nunavut and the Northwest Territories NWT pay more than 30 CND cents/kWh (even after subsidy) for their electricity bills which is three times higher the national average electricity price [3] as presented in Fig. 1 .

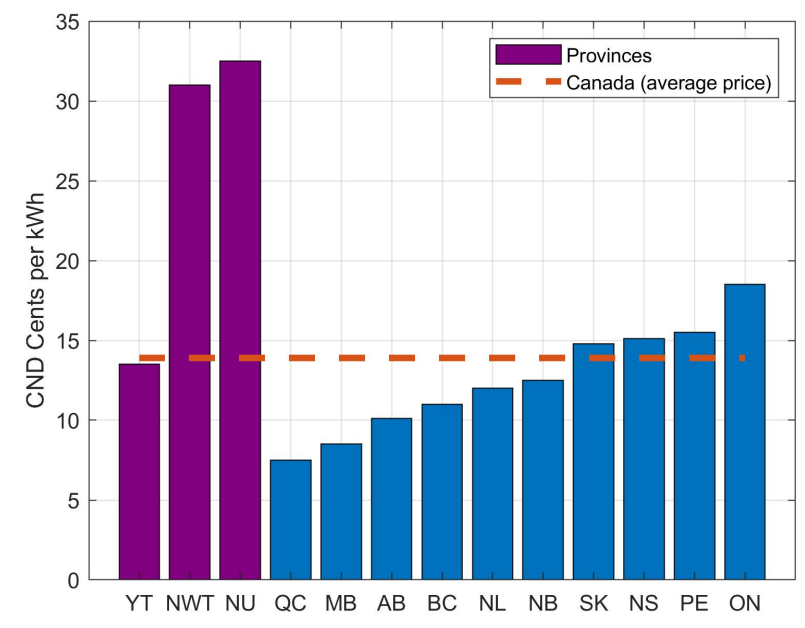

Figure 1: Household electricity prices in major cities for each province and territory (after subsidy) in 2016; data from National Energy board of the Government of Canada [3].

\footnotetext{
${ }^{1}$ The North in Canada politically refers to the territories of Yukon, Northwest Territories NWT and Nunavut; the use of the term Canada's Arctic for this work is inclusive of the three territories mentioned.
} 
Poelzer et al. 44 described the Arctic as a region that can play a critical part in the global transition to carbon neutral forms of energy by transferring knowledge to other remote communities that can use and build more sustainable integrated energy systems of their own. Hence, this research adopts a community in Northern Canada as a case study of the developed energy modeling framework and highlights the potential of the Arctic from a global perspective. As a country with more than $40 \%$ of its landmass belonging to the Arctic region [5], Natural Resources Canada [6] launched its Indigenous Off-diesel Initiative program to support Indigenous communities in developing and implementing ambitious plans to reduce diesel use for heat and power.

\subsection{Overview of the energy situation in the North and various energy system modeling approaches}

The Northern territories are facing energy challenges unique in Canada: high rates of fuel poverty ${ }^{2}$, volatile fuel prices (both for heating and electricity), increased risk of fuel oil spills during fuel transport and storage, catastrophic rise of Arctic temperatures at twice the global average rate $[8$, and the financial burden of significant government subsidies for energy costs. These challenges leave the communities exposed to various risks. For example, during the summer of 2019 in Paulatuk, NWT, the annual diesel barge did not arrive because of extreme fall ice conditions that shut down marine traffic through the area. The territorial government had to fly-in 600,000 litres of diesel to the community of 265 people to keep the mostly obsolete diesel generators running. This operation cost $\$ 1.75$ million CND over dozens of flights [9].

Recent studies have explored accelerating implementation of diesel alternatives and other energy solutions in the Arctic. Along with other organizations, the World Wildlife Fund (WWF) is at the forefront of assessing techno-economic feasibility of various low carbon technologies for the region. For instance, a two-step procedure was applied in the pre-feasibility stage of the WWF study [10. First, 25 communities in Nunavut were analyzed based on high-level renewable resource profiles (solar and wind) and energy consumption of each municipality; 13 areas were then selected to advance for further analysis using Hybrid Optimization of Multiple Energy Resources (HOMER software [11] developed by the National Renewable Energy Laboratory in the United States. HOMER determines the most feasible configuration by applying a full factorial design of experiments and choosing the configuration with minimum Net Present Cost $(N P C)$ [12].

For the feasibility phase [13, WWF developed a Mixed Integer Linear Programming model to improve the results of their pre-feasibility assessment. They used community-specific data and timelines to provide a community-level simulation for each year over a 20-year period. The study considered more detailed parameters that were only broadly approximated in the pre-feasibility study, including diesel generator efficiency curves, wind-turbine power curves and unit capacity of renewable energy $(\mathrm{RE}$ equipment as well as battery storage. For both stages of the study, WWF concluded that a microgrid or a Hybrid Renewable Energy System HRES composed of wind turbine $(\mathrm{WT})$, solar photovoltaic $(\mathrm{PV}$, , power converter $(\mathrm{CONV})$ and back-up sources of

\footnotetext{
${ }^{2} \mathrm{~A}$ household may be described as experiencing fuel poverty when it spends more than $10 \%$ of its income on utilities [7].
} 
power from a diesel generator (DG) and batteries (BT) would be economic for such Northern communities.

To investigate various energy modeling approaches without necessarily focusing on the Arctic, this section looks at various modeling techniques as applied to integrated energy systems. For instance, Sugihara et al. [14 developed a multi-objective optimization model for designing urban energy system alternatives in Osaka, Japan. The model simultaneously minimized cost, primary energy consumption and carbon dioxide emissions of the energy service system delivering electric and thermal energy in an integrated manner. Similarly, Lo Cascio et al. [15] studied an integrated energy system model consisted of small scale urban electrical, thermal and gas grids. The economic and environmental metrics evaluated in the study were quantified and verified with the commercial proprietary software, Honeywell UniSim Design Suite. Orehounig et al. [16] carried out an energy hub method in integrating decentralized energy systems at a neighborhood scale. The energy hub concept managed the relation between input and output energy flows in order to evaluate energy-autonomy and ecological performance of integrated energy systems. Cabrol and Rowley [17. conducted a simulation analysis of building-integrated air-source heat pump ASHP systems for various locations in the United Kingdom. The study also investigated the impacts of varying building enclosure characteristics. The results showed that the total operational costs and carbon dioxide emissions were lower for ASHP than for a comparative gas boiler heating system. Renaldi et al. 18 investigated a similar study by looking at heating system electrification through heat pumps installation in combination with renewable power generation. Through linear programming as formulated in Pyomo 4.0 and solved with CPLEX 12.6.2, the main optimization problem of the study was to find the optimal size and operational profile of the energy system in order to minimize total cost. Their study concluded that the renewable energy incentive programs/tariffs made the heat pump systems cost competitive against conventional heating systems.

\subsection{Research gaps and research questions}

The literature survey indicates that various component sizing methods for integrated energy system are available, but are not yet applied to remote communities especially in the Arctic. Also apparent from previous work - component sizing methods in conjunction with demand side modeling, specifically of heat load reductions, are generally scarce. Most studies focused on the supply side aspect of optimization and neglected the impact of demand-side modeling, specifically the effect of high-performance building enclosures. The latter is significantly cheaper to implement in achieving decarbonization targets, as opposed to building new energy systems with intermittent renewable resources. In some cases, heating can also be expensive enough that some households are forced to live in cold homes, which can increase the risk of physical and mental health problems 9. Hence, this study proposes a holistic and integrated energy systems approach in modeling and evaluating various energy solutions in Northern remote communities.

Specifically, previous Arctic energy system investigations will be improved by considering the complex trade-offs of designing integrated energy system in remote communities through multi- 
objective optimization. Policy makers study the North from different viewpoints, thus, there exist multiple solution philosophies in investigating a wide array of energy solutions in reducing diesel dependence in the territories of Canada. For this purpose, a Multi-objective INtegrated Energy System (MINES [19] model, based on a Genetic Algorithm GA, has been formulated to determine the drivers of energy vulnerabilities to better understand the trilemma of challenges relating to energy security, affordability and environmental sustainability. In line with this, a quantitative approach to describe and address the energy trilemma has also been found lacking in previous studies.

Another gap from the literature is related to domestic heating analysis, as most research applied to Northern Canada has been focused on electricity aspects. According to Gilmour et al. [2], heating is the most dominant form of energy use in the territories with diesel and heating oi ${ }^{3}$ as the most frequent fuel used to generate heat. In 2011, reports showed that Northeners consumed 219 million litres of diesel (and some propane) for heating alone. To put this figure into perspective, in the same year 76 million litres of diesel were consumed for power generation [20] making heat more than $70 \%$ of the combined heat and electricity demand of Canada's territories.

This paper will give significant focus and discussion on heat loads to complement the vast research that has been undertaken already for the electricity sector among Northern remote communities. For instance, Fig. 2(a) shows the amount of domestic heat generated in the Arctic territories of Canada wherein heating oil is the largest heating source across the three territories because of its reliability, especially during winter. Further, Fig. 2(b) illustrates that the annual home heating costs in the NWT are significantly higher than in southern regions of Canada like Edmonton. Wood is also widely used for home heating in combination with other heat sources such as heating oil and propane 21]. However, unlike Yukon and the NWT, Nunavut and communities farther North in the Arctic circle have limited access to wood and other types of biomass, thus limiting its use as a viable heat source among Nunavummiut [20].

Considering the expensive fuel prices in Northern remote communities, the unique energy profile in the Arctic which is predominantly heating, and the drive to respond to a rapidly changing Arctic environment while improving quality of life in the region, the motivating research questions for this work are the following:

1. How can electricity and heating generation systems be effectively linked into one integrated energy system?

2. What heating alternatives will be viable in the North while considering flexibility of integration for current and future energy systems?

3. What low-cost initiatives are available to accelerate clean energy transformations in remote communities?

\footnotetext{
${ }^{3}$ Heating Oil is a generic industry term that covers a variety of potential products, formulations, and compositions. Standard Road Diesel \#2, Diesel \#1, Kerosene, K-1, Jet Fuel, JP-1, Agricultural Diesel, Diesel \#2, Home Heating Oil / Fuel Oil \#4, or Home Heating Oil / Fuel Oil \#6 may be sold and used for heating [2]
} 

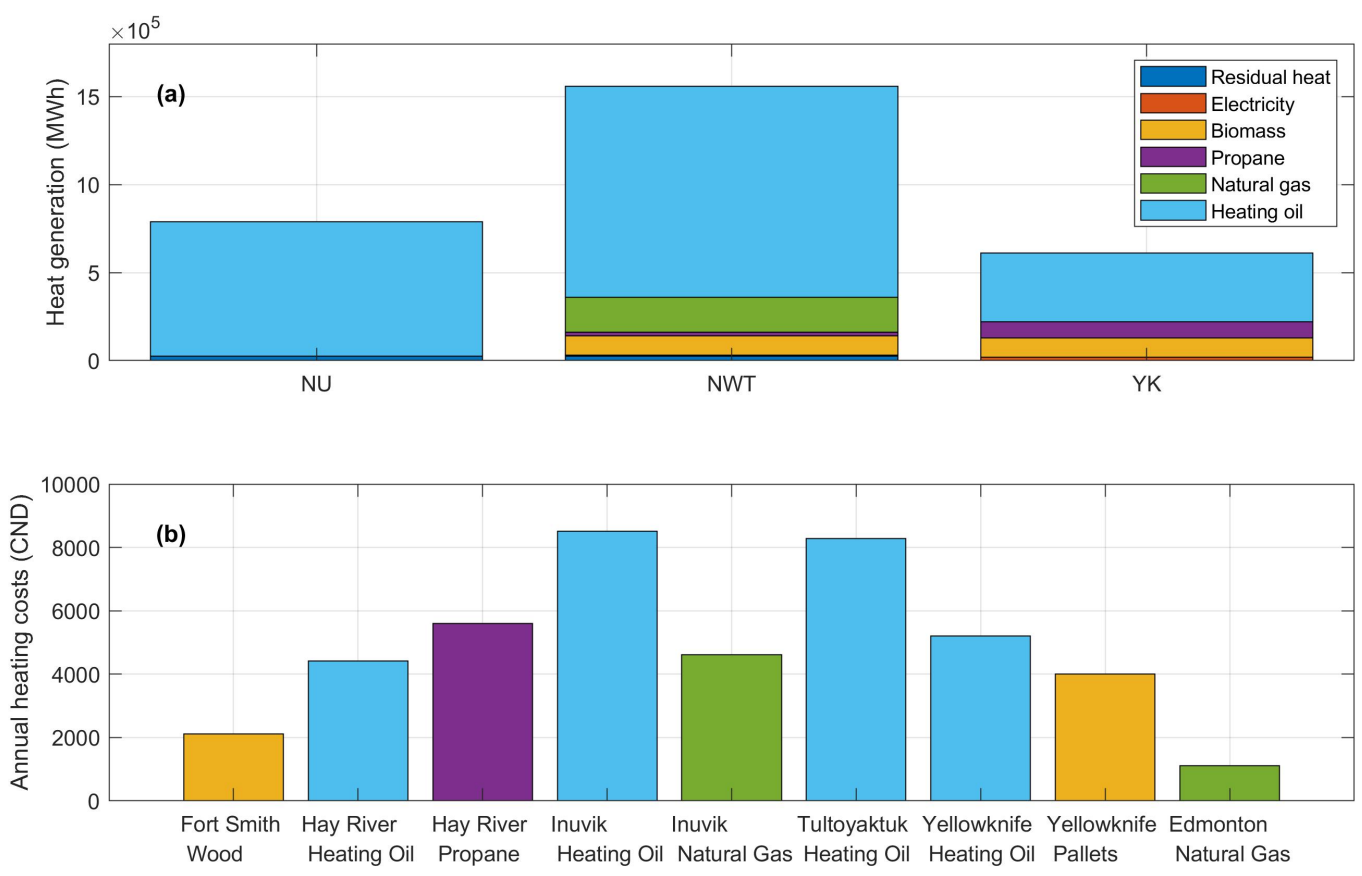

Figure 2: Heat load: (a) Heat generation by source across all territories 20]; (b) Annual community home heating costs in NWT 21.

4. What are the trade-offs between optimal solutions in transitioning towards alternatives to diesel energy?

5. What are the socio-economic impacts of implementing new sustainable energy solutions in the Arctic region?

\subsection{Study objectives and key contributions}

Just recently, WWF released its latest energy report [22] for the North by including heat in their HOMER analyses. However, it was a simplistic representation of an energy system by diverting and assuming that all excess electricity from the HRES will be used to meet the heat demand of a community. Thus, the main objective of this work is to contribute and bridge the gaps of previous Northern energy feasibility studies and answer the previously mentioned research questions by having a holistic and combined investigation of the electrical and thermal energy systems.

The primary contribution of this work is in establishing the connection between research, development and the implementation of emerging modeling approaches in real-world decision-making process concerning energy planning in remote communities. Additionally, the five key research questions of this study are addressed by the specific key contributions of this work:

1. Development of a time-series heat load building model coupled with the concurrent electrical load of Northern latitude communities;

2. Assessment of heat source alternatives such as ASHP and electric baseboard heaters while evaluating overall impact on the integrated energy system; 
3. Demand side modeling incorporating a building enclosure-focused approach and overview of possible energy efficiency measures which are key in holistically addressing energy solutions in remote communities;

4. Dynamic simulation and optimization algorithms that can capture complex trade-offs in the energy system design space using the Multi-objective INtegrated Energy System MINES modeling framework;

5. Formulation of a community-scale energy trilemma index model using outputs from the multi-objective algorithm which can holistically encapsulate various energy solutions and viewpoints relevant to policy makers and stakeholders in remote communities.

The rest of the article is organized as follows: Section 2 describes the models developed for the study. To demonstrate functionality of the models developed in Section 2 Section 2.5 presents relevant information for the community of Sachs Harbour (a community in the NWT) ; the information presented will serve as input data for the models. Section 3 summarizes the results of the test case for the method, with conclusions and future work presented in Sections 45.

\section{Methods}

Multiple combinations of technologies can be considered in designing an integrated energy system. In the specific instance of the current case study, the microgrid system consists of WT, solar $\mathrm{PV}, \mathrm{BT}, \mathrm{DG}$ and a bi-directional converter to handle power flows from the DC bus to AC bus and vice versa (Fig. 3). In terms of load, the modeled microgrid system must meet both heat demand (space heating and domestic hot water (DHW) and electricity (lighting and consumption from home appliances) for each 1 hour timestep over a given year. As shown in Fig. 4 , a systemof-systems approach was implemented across the simulation and optimization algorithms wherein the constituent sub-systems are brought together in one integrated electrical and thermal energy system.

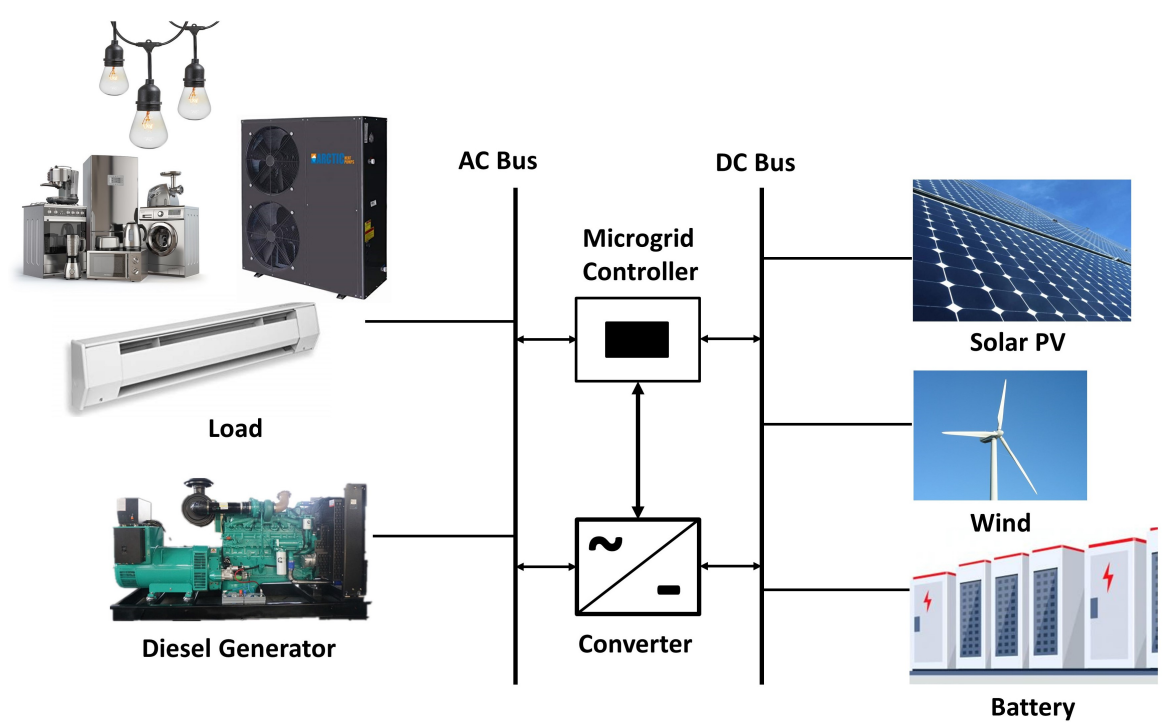

Figure 3: Schematic diagram of an integrated electrical and thermal energy system. 


\subsection{Genetic algorithm optimization}

To capture the complex trade-offs in designing integrated energy systems, a multi-objective approach is implemented which utilizes a meta-heuristic optimization process based upon on a Genetic Algorithm $(\overline{\mathrm{GA}})$. This is a population-based search and optimization method which mimics the process of natural evolution [23]. Specifically, the Non-dominated Sorting Genetic Algorithm II (NSGA-II] of Deb et al 24] has been adapted for this work as it has the generic ability to handle multi-objective trade-offs and Pareto pursuit. This has been demonstrated in various research works such as that of Evins et al. 25], Forde et al. [26, Roberts et al. [27] and Zhang et al. 28, among others.

A GA approach was chosen to be the most appropriate algorithm for this study as it can solve multi-objective and non-linear optimization problems without requiring information from derivatives of the objective functions. Also, the required computational time is still relatively low as compared to other optimization techniques since the integrated energy system in question does not possess a large number of design variables and constraints [29]. Its reliability, accuracy and convergence in finding global optimal solutions have been proven in studies conducted by Campana et al. 30] and Zhang et al. [28, among others. As presented in Fig. 44 a GA initiates the optimization process by collecting input parameters and randomly generating an initial population sets of individuals (solutions), and evaluating their corresponding fitness function. Each iteration encompasses a competitive selection process among the individuals where the vector of solutions with the highest fitness function values are recombined through GA techniques (mutation, elitism and crossover) with a purpose of attaining higher fitness values. The recombination process stops once the convergence criterion is satisfied and the optimal solution is found. The output of a multiobjective GA is a Pareto frontier curve wherein the non-dominant solutions are further analyzed to better understand trade-offs in minimizing one objective function over the other (to be further described in Section 3 .

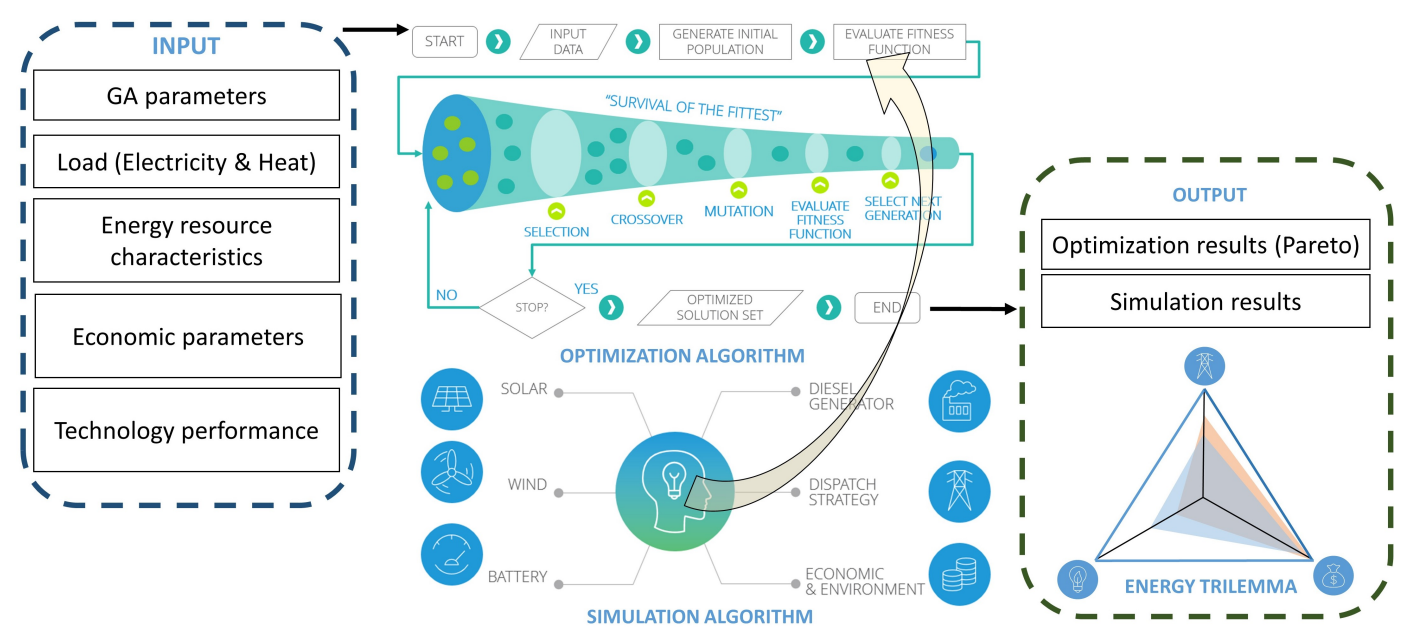

Figure 4: Multi-objective INtegrated Energy System (MINES) modeling framework.

The set of GA input parameters for this work is shown in Table 1 and the approach was implemented in a MATLAB ${ }^{\circledR}$ platform. 


\subsubsection{Objective functions}

Energy affordability is a primary concern based on the previous Energy Charettes exercise done in the Northern territories 31. Hence, the first objective function that was formulated for this study is minimizing the Levelised Cost of Energy $(L C O E)$. This economic parameter encapsulates the impact of the cost of energy to the community, together with the cost of subsidy support from the government. A modified $L C O E$ equation $[32$ that considers the full spectrum of costs from design to recycling (salvage value) as shown in Eq. 1 was used:

$$
L C O E=\frac{\sum_{t=1}^{n} \frac{C C_{i}(t)+O \& M_{i}(t)+Z_{i}(t)-S_{i}}{(1+r)^{t}}}{\sum_{t=1}^{n} \frac{P_{g e n}}{(1+r)^{t}}}
$$

where $t$ is time (year); $r$ is the discount rate $(\%) ; n$ is the total life of the energy system (year); $C C$ is the capital cost (\$) per unit of the system's component 2 is $O \& M$ is the operations and maintenance costs ( $\$ /$ year); $Z$ is all other costs associated with the project (\$/year); $S$ is the salvage value (\$); and $P_{g e n}$ is the power generated from the microgrid system (kWh/year).

In modeling and planning energy systems, there are usually trade-offs between economic and environmental goals. For this work, minimizing fuel consumption fuel cons was adopted as the second objective function to examine the interplay and trade-offs in reducing environmental emissions while ensuring low cost of energy for the community. The fuel curve describes the amount of fuel consumed by the generator in producing electricity. In this study, a linear relationship is assumed between fuel $l_{\text {cons }}$ and the DG power output. This approach has been executed in previous studies done by Sharafi et al. [33, Morse [34, and Hoevenaars and Crawford [35], among others:

$$
\text { fuel }_{\text {cons }}=F_{0} P_{D G, r}+F_{1} P_{D G}
$$

where $F_{0}$ is the fuel curve intercept coefficient $\left(\mathrm{L} / \mathrm{h} / \mathrm{kW}_{\text {rated }}\right) ; F_{1}$ is the fuel curve slope coefficient $(\mathrm{L} / \mathrm{h} / \mathrm{kW}) ; P_{D G, r}$ is the rated capacity of $\mathrm{DG}$ and $P_{D G}$ is the instantaneous power coming from the $\mathrm{DG}(\mathrm{kW})$.

The linear relationship between fuel cons $_{\text {s }}$ and the DG power output may not represent certain types of generators such as fuel cells or variable-speed diesels [36]. However, for the more common types of generators, constant-speed internal combustion generators and microturbines, the straightline fuel curve is also an appropriate fit [36. This has been proven with the fuel curves of the existing and new $\mathrm{DG}$ in a case study conducted by WWF [13]. The intercept and slope of the fuel curve are necessary so the model could extrapolate the data based on the discrete variable capacities of the $\overline{D G}$ as formulated in the GA MINES then creates the generator efficiency curve based on the power output of the $\mathrm{DG}$ and the chemical energy of the diesel fuel; this approach is adapted from HOMER [36.

\subsubsection{Constraints and other output parameters}

To depict real-world conditions in designing energy systems, certain constraints were formulated as part of the model. For example, Loss of Power Supply Probability $L P S P$ as described in Eq. 
3 37. was set to $0 \%$. This is to ensure energy reliability and that the load will be met by the energy system on an hourly timestep.

$$
L P S P=\frac{\sum_{t=1}^{T} P_{\text {deficit }}(t)}{\sum_{t=1}^{T} P_{\text {load }}(t)}
$$

where $P_{\text {deficit }}$ pertains to the insufficient supply of power from the renewables and diesel, as well as the available energy from the $\mathrm{BT}$ storage:

$$
P_{\text {deficit }}(t)=P_{\text {load }}(t)-\left(P_{R E}(t)+P_{D G}(t)+P_{b a t t}(t-1)\right)
$$

where $P_{\text {load }}$ is the electricity demand $(\mathrm{kW}) P_{R E}$ is the power produced by the renewables $(\mathrm{kW})$; and $P_{\text {batt }}$ is the energy stored in the $\mathrm{BT}(\mathrm{kW})$.

The full set of constraints considered to run the optimization module in MINES are:

$$
\text { constraints }\left\{\begin{array}{l}
L P S P \leq 0 \% \\
S O C_{m i n} \geq 30 \% \\
R E_{\text {pen }} \geq 30 \% \\
P_{\text {excess }} \leq 30 \% \\
D G_{L F} \geq 30 \%
\end{array}\right.
$$

where $S O C$ is the state of charge of the $\mathrm{BT}(\%) ; R E_{\text {pen }}$ is the $\mathrm{RE}$ penetration (\%) $19 ; P_{\text {excess }}$ is the excess electricity (\%) [19; and $D G_{L F}$ is the load factor of the DG (\%). To include a conservative assumption of introducing $\mathrm{RE}$ in the energy mix of the remote community, a $30 \%$ $R E_{p e n}$ was included in the constraints formulation. The $30 \% P_{\text {excess }}$ meanwhile, was set to avoid excess energy caused by oversizing each component of the energy system. To prevent damaging the DG by running at very low partial loads, $30 \% D G_{L F}$ was imposed in the model. Similarly, the $30 \%$ minimum $S O C$ was set to avoid damaging the storage bank by excessive discharge.

Furthermore, other output parameters that can be extracted in MINES correspond to life cycle emissions of the system. For this work, direct and indirect emission factors were adapted from Roberts et al. [27. Unlike emissions coming from fuel combustion only, life cycle emissions approaches capture direct and indirect emissions from manufacturing, transportation and decommissioning stages of the energy system. Similarly, in terms of economics, the Life Cycle Cost (LCC [38] also served as one of the model outputs to represent the sum of the cradle-to-grave economic costs of the integrated energy system for a project lifespan of 25 years.

\subsubsection{Multiple design optimization variables}

As listed in Table 2, the 11 discrete decision variables were classified into three groups in the model. The first group reflects the individual capacity of all components of the integrated energy system as presented in Fig. 3 (solar $\mathrm{PV}, \mathrm{WT}, \mathrm{BT}, \mathrm{DG}$ and $\mathrm{CONV}$ ). The second classification 
corresponds to the quantity of each component. The last group refers to the dispatch of power implemented in the model.

\subsection{Simulation}

This section describes the simulation modules that were included in this work to evaluate the objective functions of the optimization algorithm in Fig. 4.

\subsubsection{Heat load model}

For the case study of Sachs Harbour (to be further described in 2.5), a building model was developed in order to simulate the combined DHW] and space heating requirements of the community.

The daily average thermal energy demand per capita for $\mathrm{DHW} Q_{d h w}(\mathrm{Wh})$ is given by the following equation:

$$
Q_{d h w}=\rho_{w} c_{p, w} V_{d, p}\left(T_{w, h}-T_{w, c}\right)
$$

where $\rho_{w}$ is the water density $\left(\mathrm{kg} / \mathrm{m}^{3}\right) ; c_{p, w}$ is the water specific heat $\left(\mathrm{Wh} / \mathrm{kg}_{-}{ }^{\circ} \mathrm{C}\right) ; V_{d, p}$ is the daily consumption of hot water per person $\left(\mathrm{m}^{3}\right) ; T_{w, h}$ and $T_{w, c}$ are the hot and cold water temperatures $\left({ }^{\circ} \mathrm{C}\right)$, respectively. The hourly average DHW consumption profile has been derived using the profile presented in Hendron and Burch [39]. The total energy consumption for DHW has been calculated by multiplying the thermal energy demand per capita by the number of inhabitants of the community.

The total space heating requirement has been estimated as the difference between the total thermal energy demand (data from Arctic Energy Alliance [40]) and the calculated total energy demand for DHW. To calculate the hourly load profile for space heating, it was assumed that the building stock is composed of buildings with similar geometry and thermal characteristics. The hourly space heating requirement $Q_{s h}$ has been calculated using the method described in Campana et al. 30 .

$$
Q_{s h}=H L-H G+M c_{p, b} \frac{d T}{d t}
$$

where $H L$ is the heat losses $(\mathrm{W}) ; H G$ is the heat gain $(\mathrm{W}) ; M$ is the mass of the building $(\mathrm{kg}) ; c_{p, b}$ is the building heat specific capacity $\left(\mathrm{Wh} / \mathrm{kg}^{-}{ }^{\circ} \mathrm{C}\right) ; d T$ is the building hourly temperature variation $\left({ }^{\circ} \mathrm{C}\right)$; and $d t$ is the simulation timestep $(\mathrm{h})$.

The heat losses takes into account loses due to transmission $H L_{t}(\mathrm{~W})$, ventilation $H L_{v}(\mathrm{~W})$ and infiltration $H L_{i}(\mathrm{~W})$. The heat gains caused by people, lighting system, and appliances have been neglected due to unpredictability, and this approach was adapted from Campana et al. [30. It was also assumed that the internal building temperature is kept constant making $d T d t$ equal to zero. The heat gains due to solar radiation have been considered assuming a solar heat gain coefficient (SHGC) of 0.50 and a windows-to-wall ratio WWR of 0.50 . An ideal temperature controller has been assumed to keep the indoor set-point temperature always constant. The rest 
of the building simulation parameters are listed in Table $3, H L_{t}, H L_{v}$ and $H L_{i}$ are given by the following set of equations [30]:

$$
\begin{gathered}
H L_{t}=U A_{b}\left(T_{\text {in }}-T_{\text {out }}\right) \\
H L_{v}=\left(1-\alpha_{h r}\right) \eta_{v} V_{v} \rho_{a} c_{p, a}\left(T_{\text {in }}-T_{\text {out }}\right) \\
H L_{i}=\eta_{i} V_{i} \rho_{a} c_{p, a}\left(T_{\text {in }}-T_{\text {out }}\right)
\end{gathered}
$$

where $U$ is the overall heat transfer coefficient of the building $\left(\mathrm{W} / \mathrm{m}^{2}-\mathrm{K}\right) ; A_{b}$ is the total surface area of the building $\left(\mathrm{m}^{2}\right) ; T_{\text {in }}$ is the set indoor temperature $\left({ }^{\circ} \mathrm{C}\right)$; $T_{\text {out }}$ is the outdoor temperature $\left({ }^{\circ} \mathrm{C}\right) ; \alpha_{h r}$ is the heat recovery efficiency $(\%) ; \eta_{v}$ is the ventilation air changes per hour $(1 / \mathrm{h}) ; \eta_{i}$ is the infiltration air changes per hour $(1 / \mathrm{h}) ; V_{v}$ is the building ventilated volume $\left(\mathrm{m}^{3}\right) ; V_{i}$ is the building infiltrated volume $\left(\mathrm{m}^{3}\right)$; and $c_{p, a}$ is the air specific heat $\left(\mathrm{Wh} / \mathrm{kg}_{-}{ }^{\circ} \mathrm{C}\right)$.

In the absence of an actual thermal load data, it should be noted that the heat demand simulation approach estimates the thermal energy consumption of the community as a whole rather than a detailed analysis of each individual building in Sachs Harbour. Thus, the adapted heat load simulation process from Campana et al. [30] provides the worst case scenario in estimating the thermal demand of the community. This uncertainty in heat load variations will be addressed in Section 3.1.1.

\subsubsection{Component models}

The algorithm for the component sub-models $(\mathrm{PV}, \mathrm{WT}, \mathrm{BT}, \mathrm{DG})$ as laid out in Fig. 4 are detailed and have been previously described by the authors [19]. Also, a summary of the simulated characteristics of each component is listed in Tables A.13-A.16

\subsection{Operation strategies}

Two operation strategies were implemented in this work: Load following (LFOS) and Cycle charging (CCOS. The choice of dispatch strategy was also formulated as a design optimization variable in the MINES model. For both strategies, the DG only operates when the RE and BT cannot meet the load. With CCOS, the DG runs at $100 \%$ rated power until it reaches the pre-set $S O C S O C_{s p}$ of the $\mathrm{BT}$ and the excess energy is either stored in the $\mathrm{BT}$ or used to serve a dummy load if the $\mathrm{BT}$ is at a $100 \% S O C$ on a given timestep. With LFOS, the $\mathrm{DG}$ outputs just enough power to meet the instantaneous load per timestep unless it reaches the minimum power of the $\mathrm{DG}$ based on $D G_{L F}$. Finally, to handle power flows from the DC bus to AC bus and vice versa, the simulation parameters for the converter listed in Table A.17 were used.

\subsection{Energy trilemma index model}

The energy trilemma index model quantifies the three challenges (energy security, energy equity or affordability, and environmental sustainability) that have to be addressed in energy systems 
planning. These challenges can be described by three independent axes with their corresponding scoring or weighting, which have to be balanced as they imply trade-offs when looking at the impact of one axis over another. According to the World Energy Council WEC, achieving high performance on all dimensions of the trilemma entails complex interwoven links between various sectors in the society [41]. WEC comparatively ranks 125 countries based on the specific indicators of the energy trilemma [1]. Fig. 5 shows Canada's energy trilemma score. The country performs strongly on energy security and affordability but needs improvement in environmental sustainability. It has to be noted that the score was benchmarked in comparison with the other countries present on WEC $\mathrm{s}$ database, as per the WEC trilemma score definition as a comparative metric.

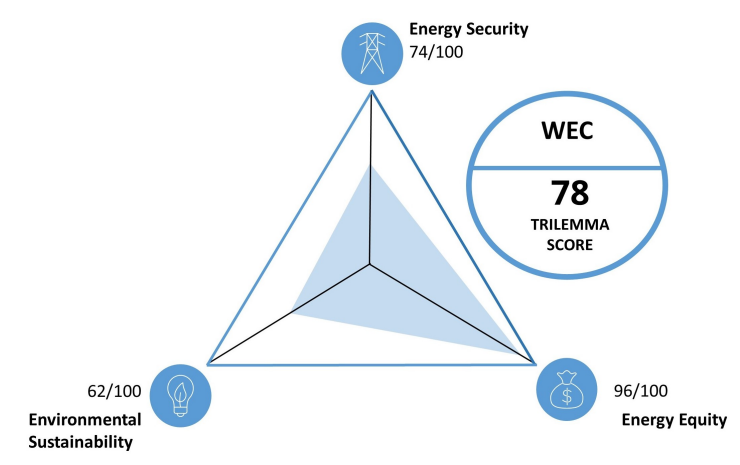

Figure 5: 2019 energy trilemma score of Canada according to the World Energy Council.

ARUP Consulting argued that the three dimensions of the energy trilemma cannot be treated independently and that all three axes are equally important, so the optimum performance implies achieving high scores on all three [42]. The firm also graphically illustrated the importance of using the tool in achieving an informed decision in energy planning as shown in Fig. 6.

The original energy trilemma index model was developed in the context of benchmarking one country against another using a specific index structure and weighting. For this work, the generated model outputs from the MINES optimization model will be extracted to specifically rank points of interest along the Pareto front, and to quantitatively assess the trade-offs inherent for each solution. In particular, the points of interest on the Pareto front will be benchmarked against other feasible solutions using the index structure presented in Tables 4 and 5 .

\subsection{Case study input data}

The methods described in this section will be applied to a case study in Sachs Harbour (Lat: 71.9884 N; Long: 125.23935 W), the Northernmost community in the NWT This Hamlet has a population of around 130 people with their main source of electricity and heat being diesel and heating oil, respectively. The fuel is shipped via barge once a year since year-round road access is not available.

Fig. 7 shows the simulated thermal load profile of Sachs Harbour using the methods detailed in Section 2.2.1. Fig. 8, meanwhile, clearly shows that the load profile of the community is predominantly from the heating load. The electrical load data has been directly provided by the 


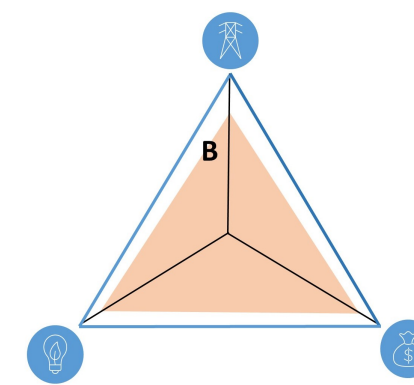

Step 1: Set the desired position

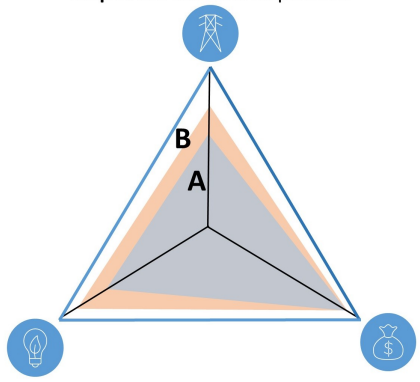

Step 3: Test new milestones, policies, projects to see if they move from $A$ to $B$

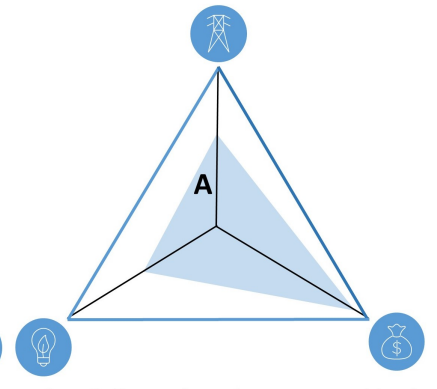

Step 2: Know where the current position is

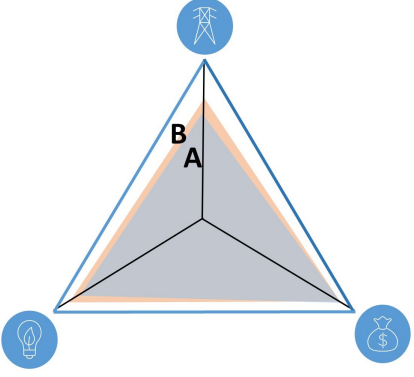

Step 4: Identify further initiatives that will compensate for the insufficiencies of those in step 3

Figure 6: Graphical representation of energy trilemma index tool in understanding existing influences and drivers in balancing three components of the energy trilemma; adapted from ARUP Consulting Company [42.

Northwest Territories Power Corporation (NTPC). The maximum and minimum electrical loads are $220 \mathrm{~kW}$ and $70 \mathrm{~kW}$, respectively. On the other hand, the peak load from the simulated heating demand is around $885 \mathrm{~kW}$.

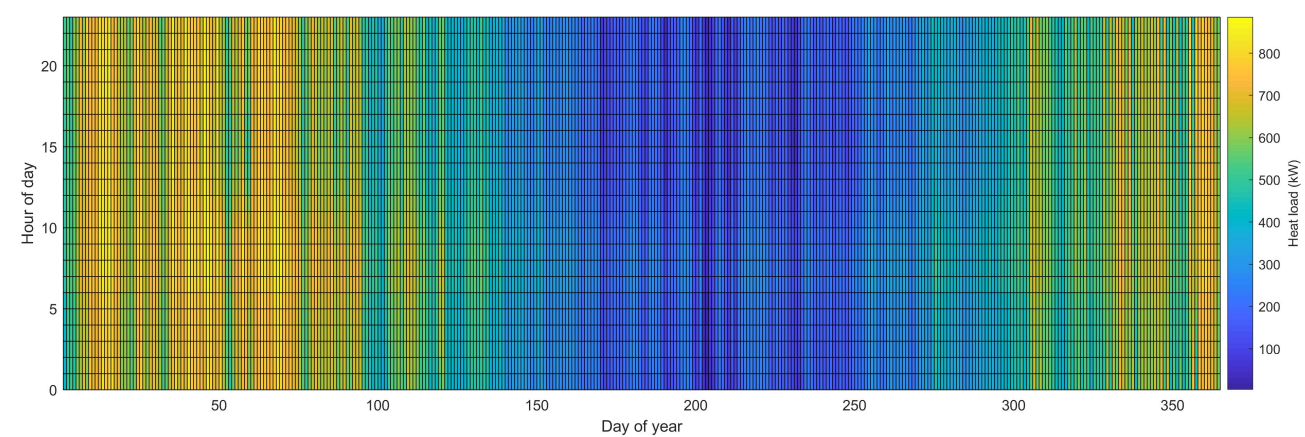

Figure 7: Heat map of thermal demand in Sachs Harbour over a year.

Although no on-site investigation has been done in terms of the actual conditions of building infrastructure in the community, a 2019 community survey from the NWTs Bureau of Statistics 43 indicated that the $30 \%$ of dwellings in Sachs Harbour have housing issues. The report focuses on housing indicators such as affordability, suitability and adequacy. A dwelling is described as affordable if the household is spending less than $30 \%$ of their income on housing costs. A house is considered adequate if it does not require major repairs. Suitability is defined as having the appropriate number of bedrooms against the number of occupants. No detailed discussion was given in the survey but it was assumed that the high heating demand is related to major housing repairs needed in specific houses and buildings in the community. 

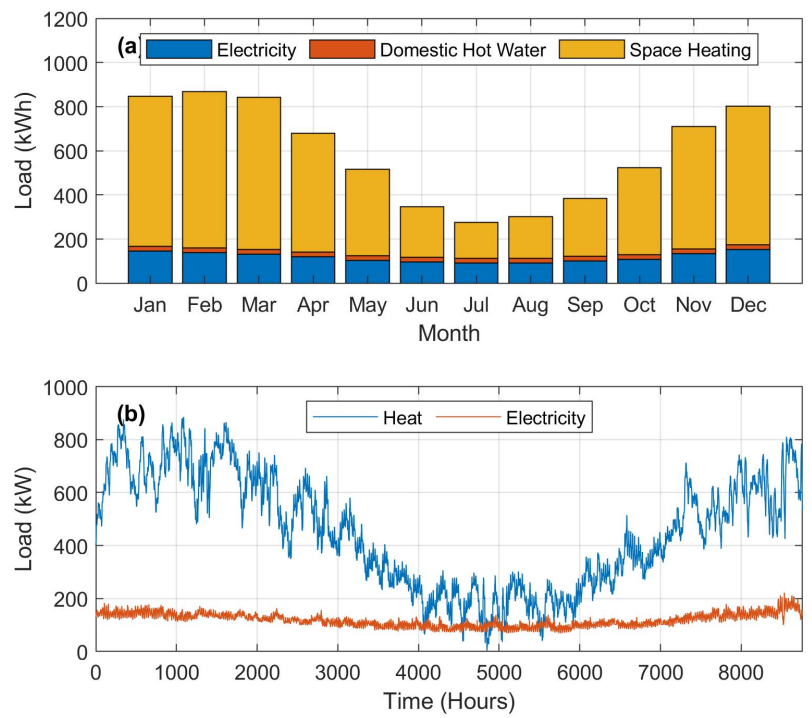

Figure 8: Integrated load of Sachs Harbour: (a) Average monthly load; (b) Hourly electricity and heat load.

Further, wind tower data measurements at 30m height with 10-minute temporal resolution from July 8, 2005 to September 29, 2009 were supplied by the local government of the NWT for this work. The wind velocity data were extrapolated to a $40 \mathrm{~m}$ height using the method described in Quitoras et al. [19]. As shown in Fig. 9(b), high wind speed registries can be observed during autumn and the mean wind velocity for the year is around $8 \mathrm{~m} / \mathrm{s}$ after extrapolating the data to a $40 \mathrm{~m}$ height. Another climatic parameter that affects the operation of the energy system is the solar resource. Fig. 9(a) shows low GHI during autumn and winter due primarily to the high latitude of Sachs Harbour. The temperature profile of the community is in Fig. 15 and will be discussed further in the results section.

\section{Results and discussion}

This section presents the results from executing the methods discussed earlier. The outputs were further analyzed by performing scenario analyses of various energy system configurations while looking at practical implementation approaches to realize the goals of this work. This section ends with a validation exercise for the proposed model.

\subsection{Design optimization and simulation results}

The full design space exploration by the GA of the energy system is shown in Fig. 10, The simulated heat load is assumed to be supplied by using electric appliances for DHW (specifically via instant water heating devices) and via electric baseboard heaters for space heating demands respectively. Fig. 11 presents the variations of the objective functions during the optimization process. It can be seen that a wide range of values are visible at the beginning of the optimization process, with convergence to uniform values evident from around the 130th generation forward. This means that the optimizer can no longer improve the calculated objective function values 

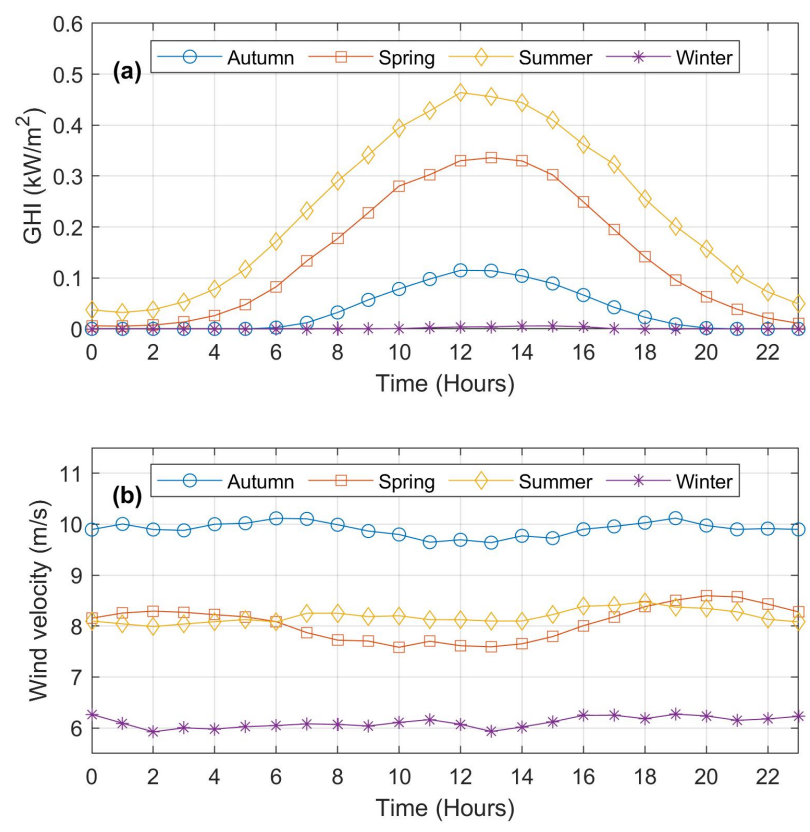

Figure 9: Meteorological data for Sachs Harbour for different seasons: (a) Average extrapolated wind speed at 40m elevation; (b) Average hourly Global Horizontal Irradiance (GHI).

and a solution has been attained. Increasing the population size and the number of generations in the GA optimizer covers the solution space more thoroughly, but will cause the algorithm to run slowly. This investigation has been performed, but the Pareto front did not change and the solutions converged to uniform objective function values at the 130th (approximately) generation as well. This confirms that the chosen GA population size and the number of generations in Table 1 are sufficient to carry out the modeling work in this study.

In a multi-objective optimization, the superiority of a solution is determined by the concept of solution dominance [38. In Fig. 10, the blue dots represent the dominated solution points while the points in orange (Pareto front) are the non-dominated solutions. Unlike in single-objective optimization problems where the output is presented as a candidate solution, output for a multiobjective optimization technique is presented as a set of candidate solutions. This approach yields diversity of solutions to be able to analyze trade-offs between two conflicting design objectives.

From the Pareto front in Fig. 10, it is clear that as $\mathrm{fuel}_{\text {cons }}$ decreases, the $L C O E$ of the energy system increases. As described in the objective function formulations, minimizing fuel $_{\text {cons }}$ impacts this aspect of the feasible solutions. In particular, this limits the operation of the DG and the power is compensated by including RE technology and BT storage. However, this reflects a trade-off wherein the resulting system's $L C O E$ increases. The discontinuity in the Pareto front is influenced by the lower and upper bounds of the discrete characteristics of the decision variables as shown in Table 2, and the restrictions implemented in the constraints formulation of the model. The reason for the final step-change at the tail end of the Pareto front will be explained in Section 3.1 .1 . 


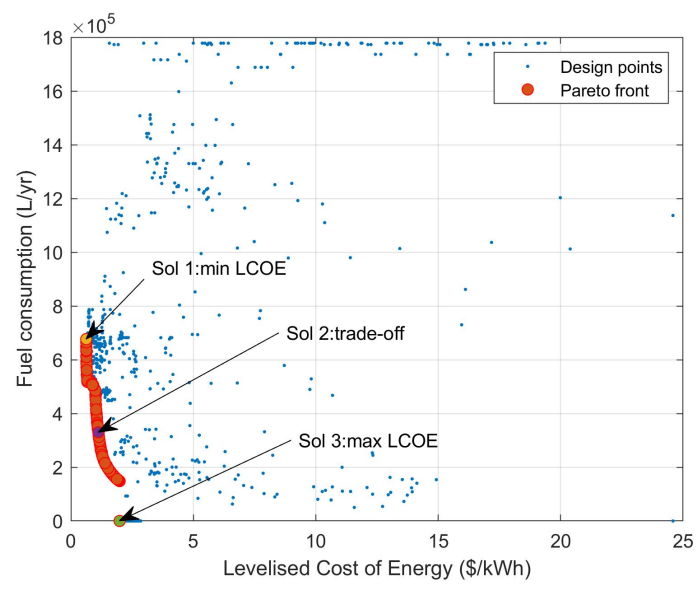

Figure 10: Full design space with the optimal Pareto front and the identified solutions of interest.
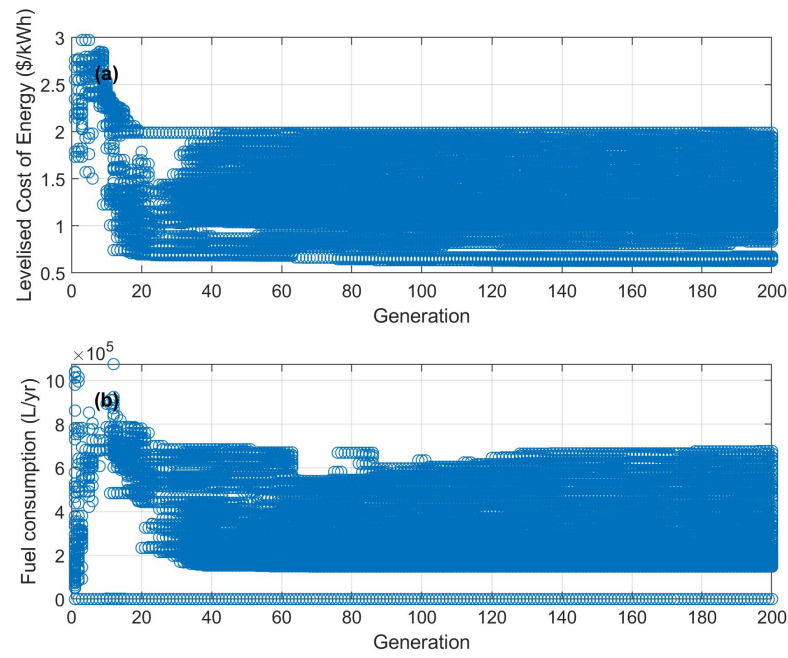

Figure 11: Variations of the objective functions with GA generations.

The three solutions of interest as specified in Fig. 10 are further examined and their system configurations are provided in Table 6. With the three solutions of interest, the WT has the largest share in meeting the energy demand. This reflects the strong wind resource in Sachs Harbour making it a viable option in displacing a significant proportion of the diesel power of the community. The BT storage helps stabilize the mismatch between the demand and the intermittency of RE. However, this causes an increase in the system's cost. In particular, solution 3 has a $100 \% R E_{p e n}$ but the increased capacity in $\mathrm{WT}(5,225 \mathrm{~kW})$ has to be matched with an appropriate level of BT storage $(14,630 \mathrm{kWh})$ which is almost three times the capacity of solution $1(4,620 \mathrm{kWh})$. A trade-off point (solution 2) located approximately at the middle of the Pareto front has a system configuration and characteristics that balance the results calculated from solutions 1 and 3 . Solution 2 has all the system components presented in Fig. 3 The system's LCOE (1.1212 CND $\$ / \mathrm{kWh}$ ), however, has doubled from the solution 1 since it has higher $\mathrm{RE}$ capacity with a larger BT storage capacity. Nonetheless, the fuel $l_{\text {cons }}$ of the DG is about $50 \%$ less than that of solution 1. This trade-off analysis is fundamental in analyzing all feasible options from the decision maker's 
point of view.

The optimal dispatch control strategy of the integrated energy system is LFOS. This result was influenced by the load profile of the system. Using the same decision variables in Table 2 and excluding the heat demand in Fig. 8(b), the MINES model was run again. Table 7 shows the comparison of the optimal configuration results for the system both with and without the heat load (cases 1 and 2 respectively). The tool selected CCOS as the optimal dispatch strategy when the load is only related to non-heating electrical demand. As mentioned previously in Sec 2.3. the two dispatch controls are similar except LFOS only produces enough power to meet the instantaneous load while $\mathrm{CCOS}$ operates at its rated power and excess energy is stored in the BT during operation. Hence, it can be deduced that the optimal dispatch approach could also greatly affect the optimal DG capacity of the system. From Table 7 , it can be observed that the optimal DG capacity is influenced by the total energy demand along with the peak load. For example, in case 2 , the peak electrical load for the system is $221 \mathrm{~kW}$ with an optimal DG capacity of $225 \mathrm{~kW}$. Case 1, on the other hand, has a peak load of $1,036 \mathrm{~kW}$ with an optimal DG capacity of 1,125 $\mathrm{kW}$. These optimal DG capacities ensure that the peak loads will be met throughout the year. However, how to dispatch these capacities from the DG affects which dispatch control is optimal for the energy system taking into consideration the two conflicting design objectives mentioned previously.

The listed optimal subcomponent capacities in Table 7 are not sufficient to explain the selected optimal dispatch control given the complexity of the energy system. Hence, Fig 12 shows the impact of the load profile on the optimal hourly simulation dispatch. For both cases, it can be observed that running the $\overline{\mathrm{DG}}$ is more flexible in meeting the fluctuations of the demand than discharging the $\mathrm{BT}$ as the latter's charge-discharge cycles are affected by the amount of excess and deficit power from RE Changing the dispatch control to LFOS in case 2 would make the solution still feasible, but sub-optimal and dominated (Fig. 13(b)). On the other hand, running the DG just enough to meet the load deficit (LFOS) is more optimal in reducing the overall fuel cons of the system in case 1 . In contrast, running the DG under CCOS would make the overall system suboptimal and dominated as shown in Fig. 13(a). Although running the DG at full rated capacity is preferable and more efficient in general, doing so in this case is not necessary, as the $\mathrm{WT}$ and the $\mathrm{PV}$ are optimally scaled up (together with the instantaneous power coming from the DG) to meet the high demand and load fluctuations as compared to the previous case. Furthermore, the system tends to dispatch power coming from the $\mathrm{DG}$ during high demand season (winter) as there is not enough power to be discharged from the $\mathrm{BT}$.

Note that increasing the value of the $L P S P$ from $0 \%$ is impractical as it would entail power outage. This would be even more costly for a Northern community such as Sachs Harbour as flown in fuel would be required to meet peaks in demand or the unmet load due to the increased $L P S P$. To illustrate this in a real-world context, this activity of flown in diesel fuel cost around $\$ 1.75$ million CND over dozens of flights for the community of Paulatuk, NWT in 2019 9. 

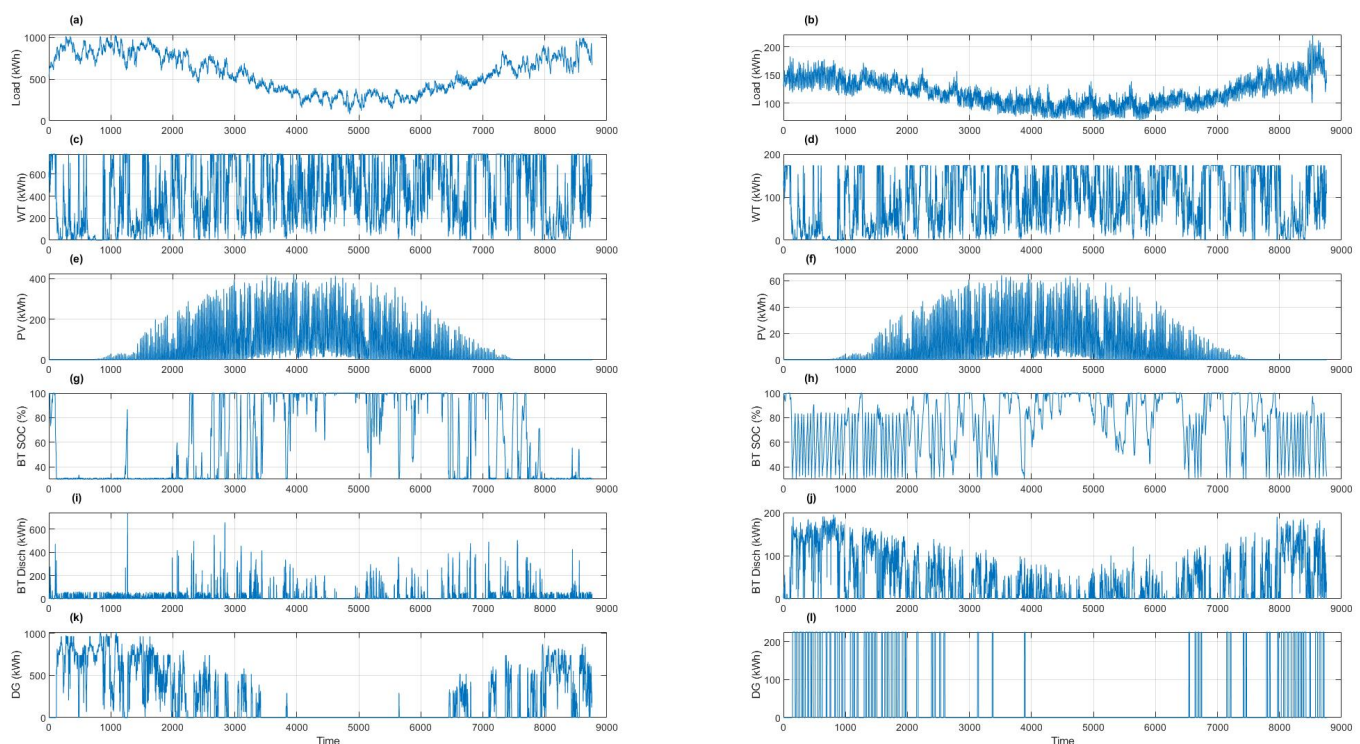

Figure 12: Impact of the load profile on the optimal simulation dispatch: (1) Case 1 (left column) is the simulation results (under load following) with the combined electricity and thermal load profiles; (2) Case 2 (right column) is the simulation results (under cycle charging) with electricity load profile only.
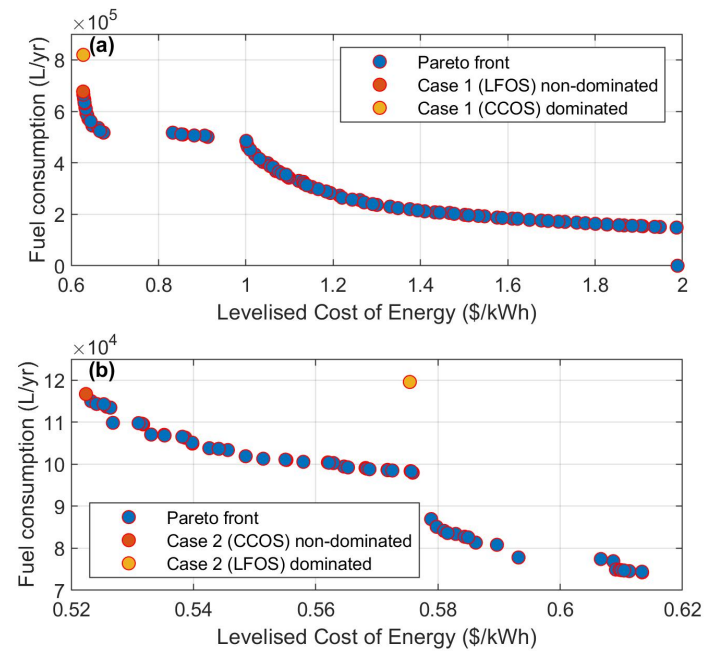

Figure 13: Changing the dispatch control would make the solution sub-optimal (dominated): (a) Case 1 Pareto front (under load following) with the combined electricity and thermal load profiles; (b) Case 2 Pareto front (under cycle charging) with electricity load profile only.

\subsubsection{Scenario evaluation and heating system flexibility}

A scenario analysis was carried out in order to evaluate candidate heating technologies in Northern remote communities. In such contexts, district heating has always been challenging due to issues of installing pipe networks on permafrost to distribute heat in the community. A report from the local government of the NWT argued that even as construction techniques improve, challenges in building on permafrost have become more evident throughout the territory [44] especially for the Northernmost communities such as Sachs Harbour. Similarly, utilizing waste heat from the 
centralized diesel facility for the majority of communities in the North is not practical as it would also involve construction of piping networks that will distribute heat to houses and buildings. Also, since one of the objective functions in this study is to minimize fuel $f_{\text {cons }}$, the resulting capacity factor of the DG is only around 10\% - 20\% which makes it even more impractical from an economic point of view.

Given these considerations, this section looks at the use of single swelling air-source heat pumps ASHP as a potentially viable option along with the use of electric baseboard heaters which were included in the study's first optimization results (scenario 1). In particular, the evaluated scenarios together with their corresponding heat sources are presented in Table 8. This section focuses on the impact of the two heating technologies while Section 3.2 analyzes the impact of an 'enclosure first' approach to the building design. Meanwhile, to calculate the ASHP s electricity consumption, the empirical relationship between $T_{\text {out }}$ and the heat pump's $C O P$ (efficiency) was used [30]:

$$
C O P=2.79+0.036\left(T_{\text {out }}\right)+0.0006036\left(T_{\text {out }}^{2}\right)
$$

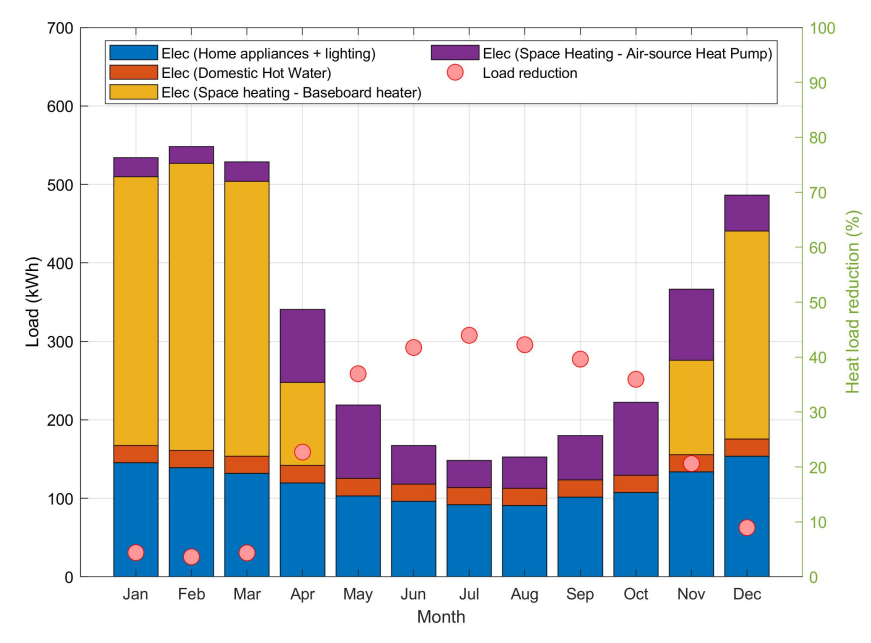

Figure 14: Scenario 3 heat load reduction caused by using ASHP and baseboard heater.

Baseboard heaters are thermodynamically close to $100 \%$ efficient; in this study it is assumed that $100 \%$ of the electrical energy consumed is converted to heat. Heat pumps, on the other hand, typically range from $200 \%$ to $300 \%$ efficient, supplying the same amount of heat from much less electrical energy. As shown in Fig. 14, a heat load reduction of about 40\% (by using ASHP is evident especially during the summer months in Sachs Harbour. However, using ASHP in the Arctic is quite challenging because of its low $T_{\text {out }}$ profile (Fig. 15). In line with this, a company 45] manufacturing ASHP designed for the Arctic has been researched. The firm claim that their heat pumps can operate even in $-20{ }^{\circ} \mathrm{C}$ with a $C O P$ of 2 . For this work, when the $T_{\text {out }}$ is below $-20{ }^{\circ} \mathrm{C}$, the ASHP shuts off and the baseboard heater kicks in (scenario 3 in Table 8 ).

In spite of the heat load reductions observed in Fig. 14, the hourly load fluctuations (Fig. 16) caused by the on and off operation of the ASHP has a negative impact on the energy system. In particular, this resulted in an increased BT capacity (and a significant step-change at the tail 


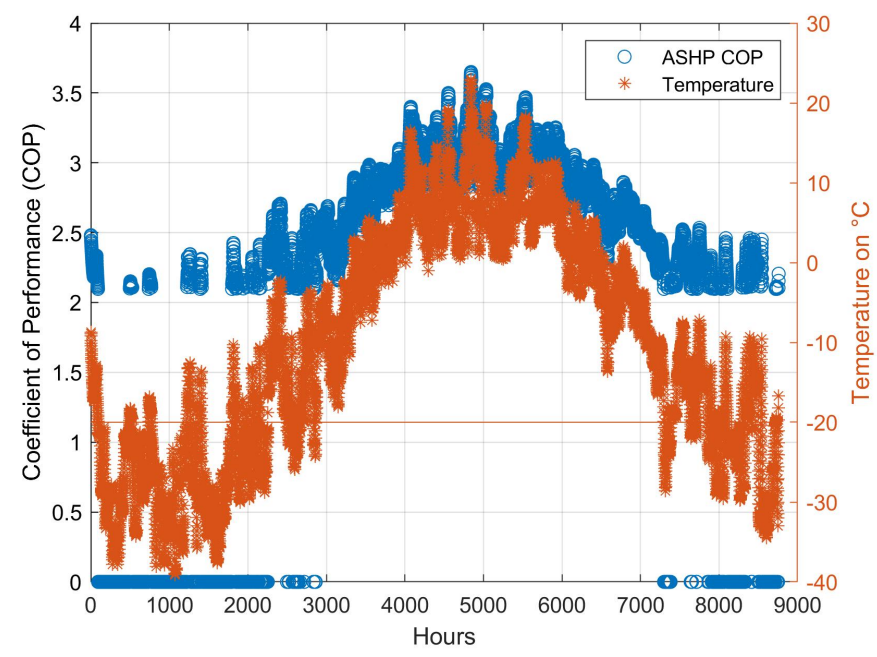

Figure 15: COP of ASHP in scenario 3; ASHP shuts off when outside temperature drops below $-20{ }^{\circ} \mathrm{C}$.

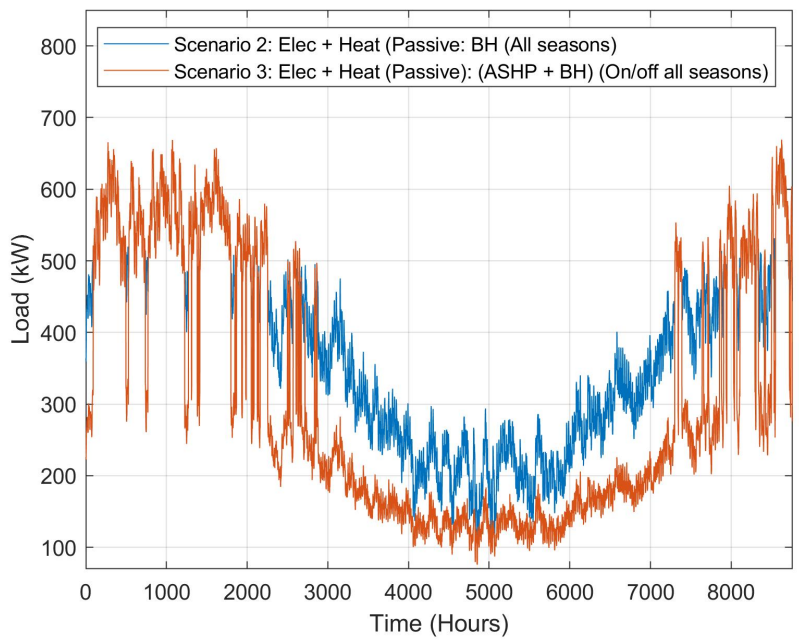

Figure 16: Hourly load fluctuations as the ASHP shuts off and the baseboard heater kicks in.

end of the Pareto front) in order to handle the mismatch and fluctuations in the energy demand. From Fig. 17, it can be seen that the optimal subcomponent capacities (DG and RE of the 100 population/individuals (also known as the $\mathrm{GA}$ solutions) in the Pareto front of scenarios 2 and 3 are similar. This is also the case for the BT storage except for the last solutions/points at the tail end of the Pareto front. For example in scenario 2, the second to last solution in the Pareto front has a DG and BT storage included in its optimal system configuration. However, for lower than the optimal DG and BT capacities, the model can no longer find a non-dominated optimal solution where both DG and BT are acting as back-up sources of power. This is influenced respectively by the lower and upper bounds of the discrete optimization variables in Table 2 , the constraints formulation, the two objective functions in the model, and the peak loads of the energy demand (to be explained subsequently on this section). As a result, the MINES model selected a zero DG capacity (lower bound in Table 2) for the last point in the Pareto front but it increased the BT storage capacity to compensate for the unavailability of the $\mathrm{DG}$. This behaviour is consistent with 
the observed fuel cons variations in Fig. 11 .

The amount of increase in BT capacity depends on the two peak loads present on the energy demand. In Fig. 18(a), non-parametric bimodal distributions of the integrated electrical and thermal loads are evident. In statistical terms, this bi-modal distribution, specifically the difference of the two maxima in scenario 2 is less than that of scenario 3. Hence, the optimal BT capacities at the tail end of scenario 3 is almost doubled as the difference of the two peak loads is also doubled (the same reason applies for scenario 2 as shown in Fig. 18).
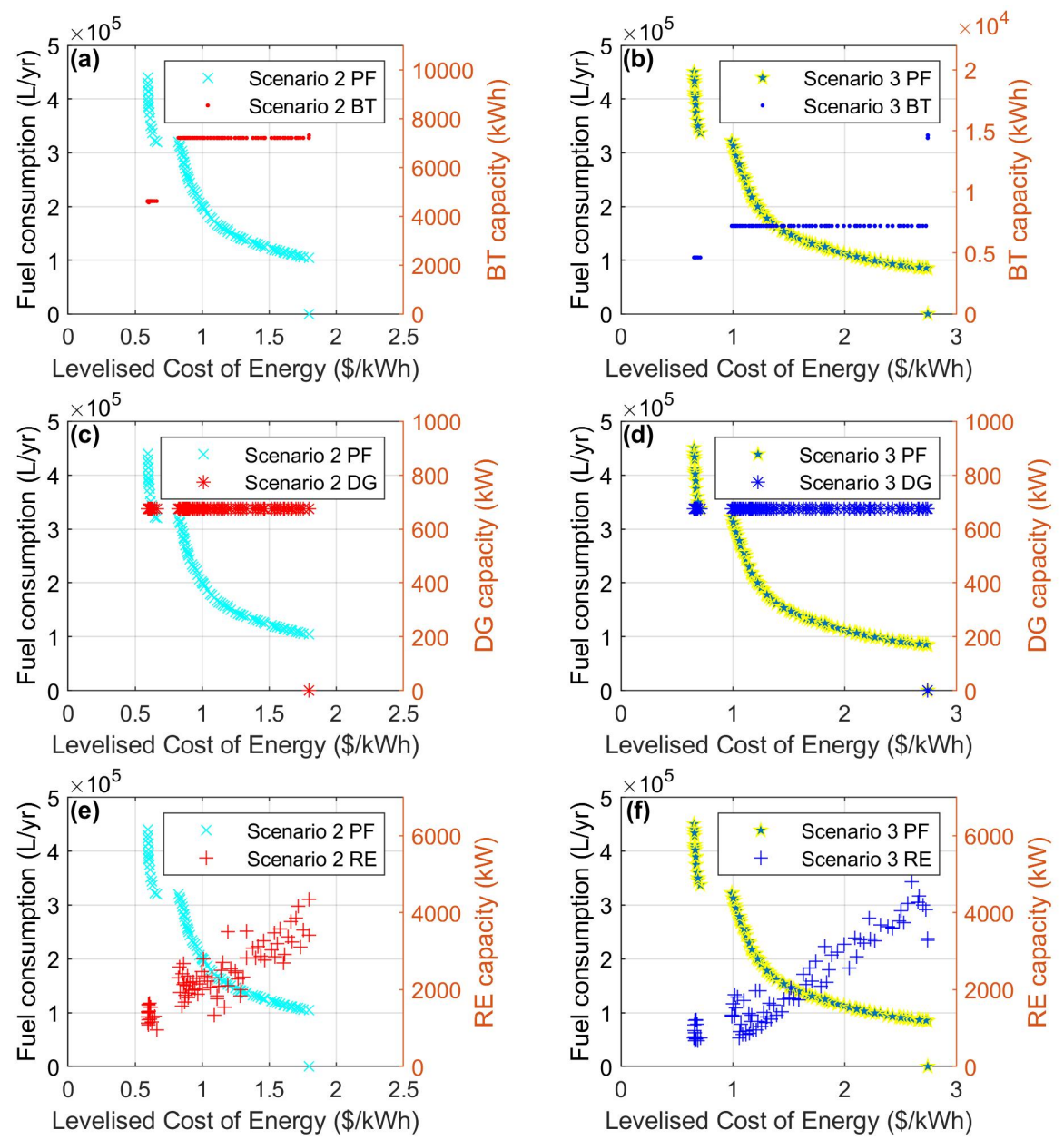

Figure 17: Comparison of subcomponents optimal capacity with Pareto front (PF) for scenarios 2 and 3: (a) BT storage - Scenario 2; (b) BT storage - Scenario 3; (c) DG - Scenario 2; (d) DG - Scenario 3; (e) RE - Scenario 2; (f) RE - Scenario 3.

The on and off operation of the ASHP may not be practical in real-world applications. Thus, scenario 4 (Table 8 has also been investigated. Under this case, the ASHP only operates during summer as ambient temperatures are more likely not below $-20{ }^{\circ} \mathrm{C}$. For the rest of the year, the baseboard heater runs. In Fig. 19(a)-(b), the resulting Pareto front and the objective function variations (whisker plots) of scenario 4 are almost the same as that for scenario 2 since the simulated energy demand is the same except during summer (as affected by the ASHP operation). However, 


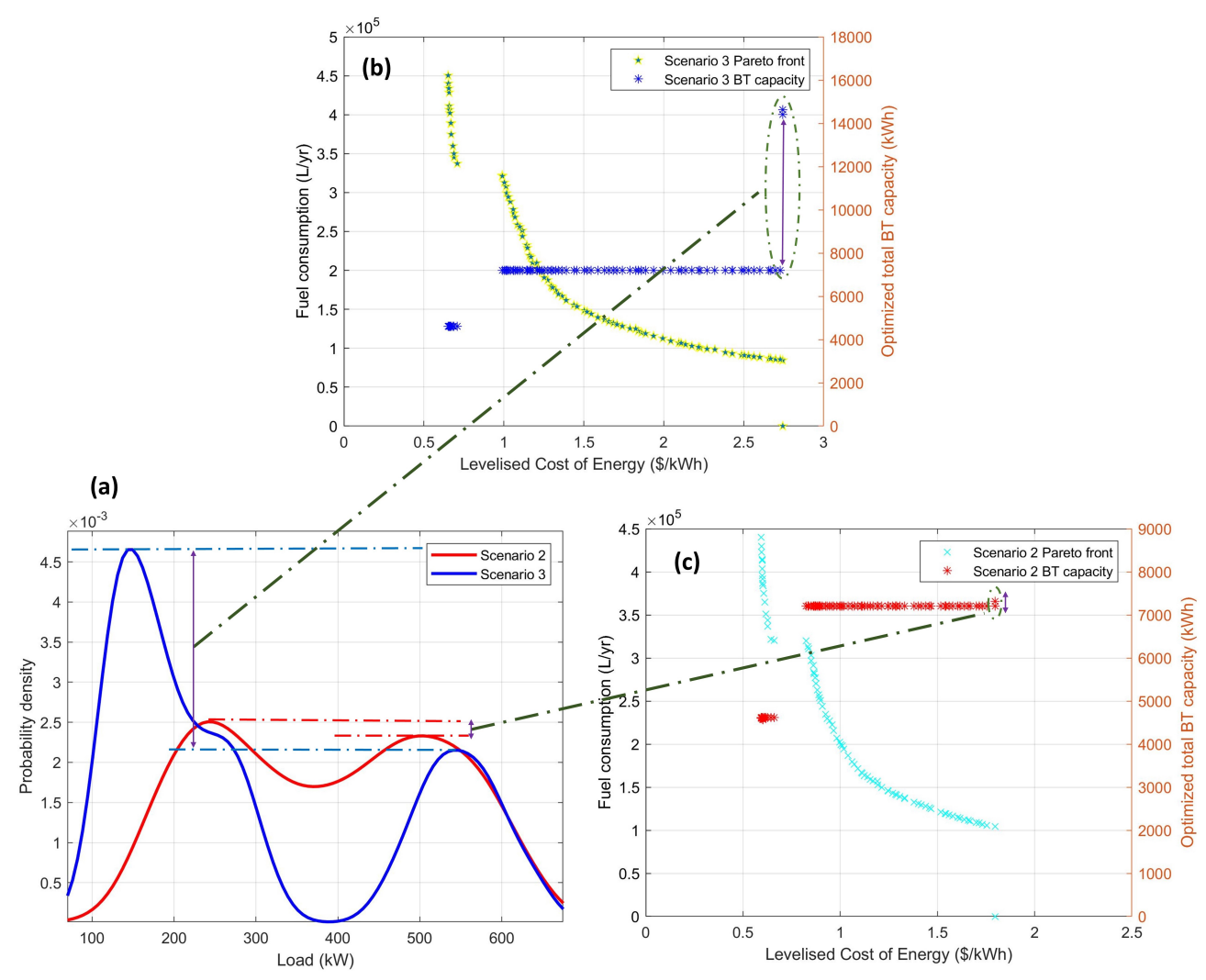

Figure 18: Comparison between scenario 2 and 3 optimization results: (a) Non-parametric bimodal distributions of integrated electrical and thermal loads; (b) Scenario 2 Pareto front with corresponding optimized BT capacity per population in GA; (c) Scenario 3 Pareto front with corresponding optimized BT capacity per population in GA.

it is observed in Fig. 19.(c) that the Pareto front for scenario 2 is still more optimal than that for scenario 4. As described in the previous discussion, the fluctuation of loads caused by the variation of the ASHP $\mathrm{s} C O P$ s resulted in a slight cost difference for the energy system, particularly due to the increase in $\mathrm{BT}$ storage capacity. This hourly variation of the $C O P$ in relation to the $T_{\text {out }}$ has also been observed to affect district heating systems operation in a study made by Pavicevic et al. [46]. Their study, however, did not look at the impact upon the BT storage or upon the integrated energy system as a whole.

\subsection{Building enclosure-focused approach}

As described in Section 1, a household is considered to be fuel poor when it spends more than $10 \%$ of its net income on utilities. The Canada Energy Regulator's recent study [7] found that households in the Atlantic provinces and Saskatchewan experience the highest incidence of fuel poverty in Canada with rates of $13 \%$ and $10 \%$, respectively. Notably, the Northern territories were excluded from this provincial-scale fuel poverty research because of the unique energy challenges faced by the people in the Arctic region. Paradoxically, the estimated fuel poverty rate in the North is about $8 \%$ using the average household utility expenditures data from CanmetENERGY 47]. However, it has to be noted that this includes a significant government subsidy for household utility bills. 

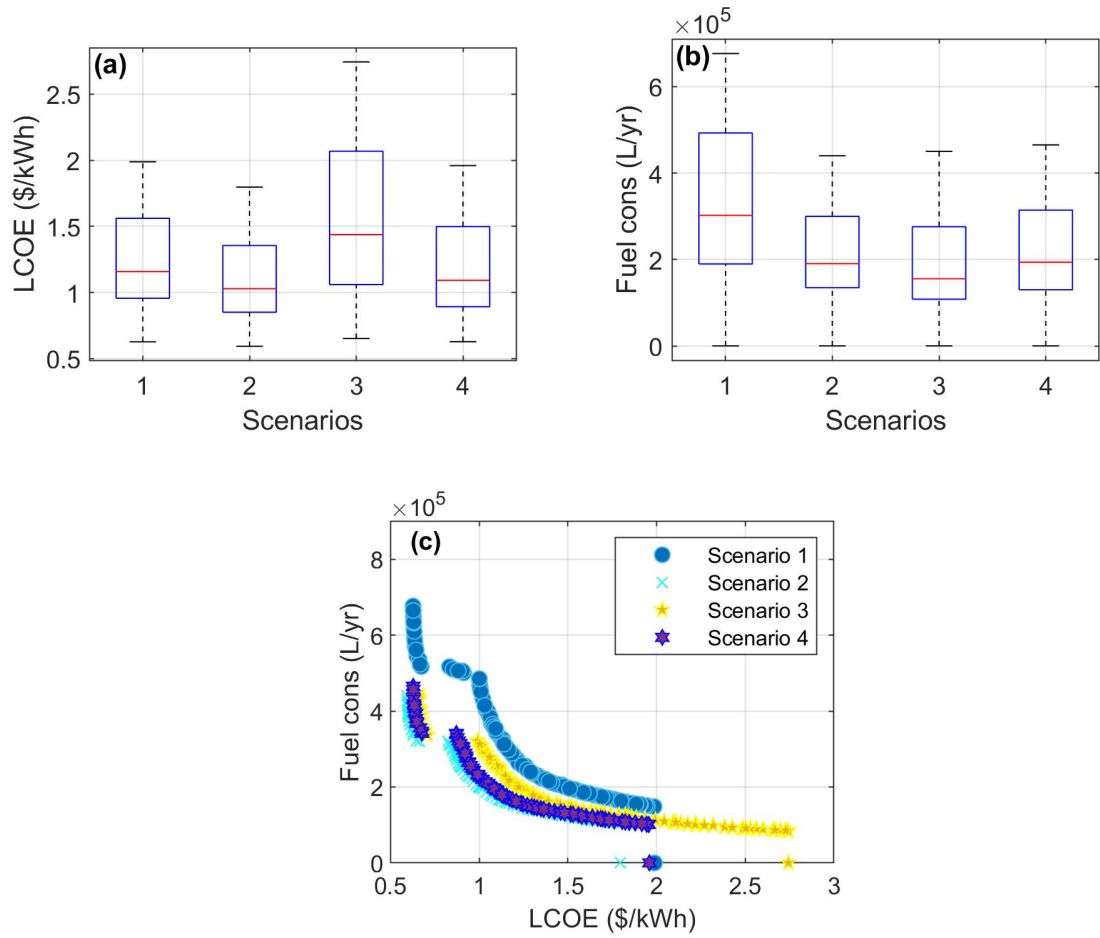

Figure 19: Design optimization results for the four scenarios: (a) Whisker plot showing the objection function variation of LCOE; (b) Whisker plot showing the objection function variation of fuel consumption; (c) Pareto fronts.

To address fuel poverty impacts, provincial and federal governments have introduced energy efficiency programs especially for low income households [7]. In line with this, Efficiency Canada also launched its first Provincial Energy Efficiency Policy Scoreboard on 2019 [48] in order to assess policies and the overall energy efficiency performance of the country. However, the Northern territories have been excluded from the research conducted for the country's fuel poverty situation.

With this framing in mind, this section aims to give an overview of the impact of using less energy (through building enclosure improvements) to achieve the same or better energy services at lower cost and carbon emissions.

In the scenarios presented in Section 3.1.1, two types of building enclosures as a function of their whole-building $U$-values were evaluated in the MINES model. These two U-values (0.5 and $0.13)$ correspond approximately to the performance of a normal and passive building respectively in Sachs Harbour. The characteristics of a passive building varies depending on certain building standards. The International Passive House Institute and the Passive House Institute US are two of the main organizations working on constructing high-performance building enclosures specifically in North America [49. They administer similar Passive House criteria that might differ depending on climate zone and other factors.

Fig. 20 shows the projected energy saved by using high-performance building enclosures in Sachs Harbour. Reduced load estimates through other common methods of improving building performance such as installation of Mechanical Ventilation with Heat Recovery (MVHR) and maxi- 
mizing air-tightness has also been conducted and the results are listed in Table 9. However, outputs show that improving the elements of building's enclosure (defined by its $U$-value) has the highest calculated load reduction $(40 \%)$ as compared with the other two methods. Hence, it has been selected to be the focus of this section and it was reflected in the performed scenario evaluations in the model.

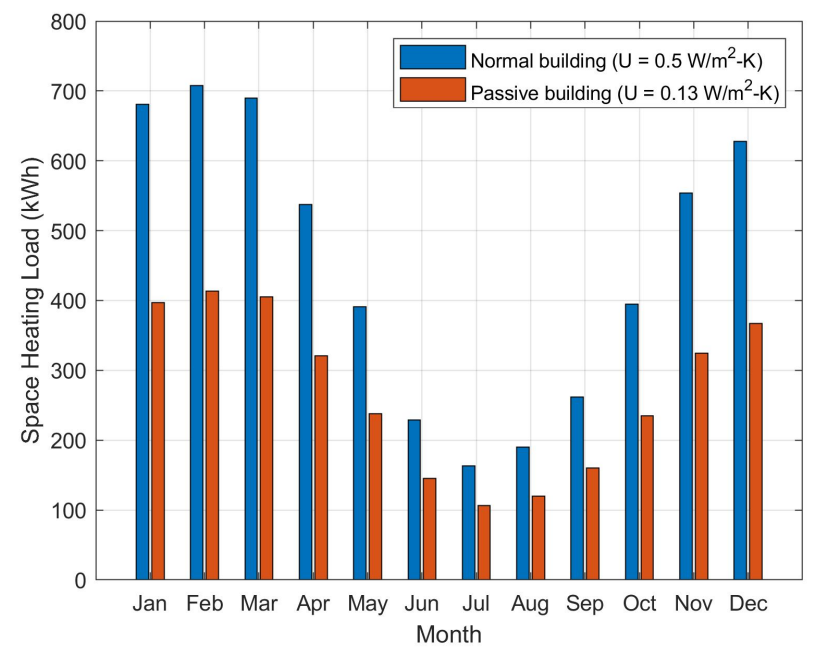

Figure 20: Average space heating load per month for the community of Sachs Harbour for using high-performance building enclosures.

High-performance enclosures also impart significant benefits apart from reduced energy demand. In particular, the results of this approach offer thermal comfort and increased resiliency to extreme temperature events and power outages which are common among remote communities in the Arctic.

Table 10 lists the investment costs of improving building enclosures for new buildings, maintenance of existing buildings (plaster repairs, facade coating), and energy efficiency refurbishment of existing buildings (12 cm external insulation) [52. With this data, the system configuration having the lowest $L C O E$ in scenario 2 was evaluated in the MINES model while looking at varying building enclosure improvements and its impact on cost and the overall performance of the energy system. Fig. 21(a) shows that the investment costs for building enclosures is relatively cheaper than investing in RE technologies. Further, Fig. 21(b) presents the robustness of the optimal configuration result against RE fluctuations and the variations of energy demand as impacted by the $U$-values of the specific types of building enclosures. It can be observed that the new building standards $U$ values of $0.15,0.2$ and 0.23$)$ and the energy efficiency refurbishment of existing buildings $(U$-value of 0.28$)$ can withstand these variations while ensuring adequate supply of power and having approximately $0 \%[L P S P(0 \%-0.24 \%)$ across the four $U$ values implemented in the model. This increase in $L P S P$ was affected by the increased space heating load as the $U$-value of the building increases. As a result, the capacity factor of the DG increased, but not enough to supply all the demand, especially to $U$ values ranging from 0.85 - 1.1 (maintenance of existing buildings). This increase in power output from the $\mathrm{DG}$ resulted to an increase on the $L C C$ of the 
system. Note that this result is heavily influenced by the availability of investment costs data for building enclosures.
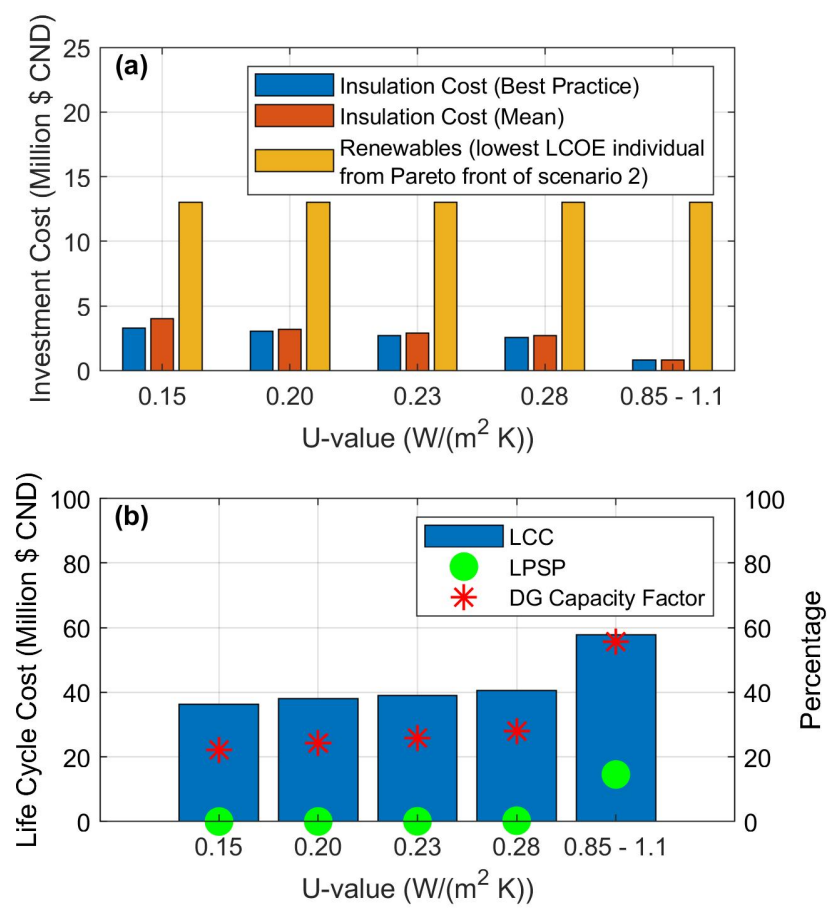

Figure 21: Projected impact of varying insulation thickness as a function of the building's U-value: (a) Investment cost; (b) Energy system performance (LPSP, DG capacity factor and LCC).

\subsubsection{High-performance building enclosures versus renewables}

It should be noted that in theory, the $L C C$ savings from implementing a building enclosurefocused approach can be allocated towards investing in RE technology options for Sachs Harbour. Also, the reduced loads can reduce both the fuel poverty incidence in the Arctic region of Canada, as well as the level of public energy subsidies within such communities. However, prioritization as to which (or both) energy solution should be adopted must be considered in the context of the decision making processes of the various relevant stakeholders in the North. In this context, Fig. 22 presents an inverted pyramid concept for the implementation of the three main energy solutions relevant to both Northern Canada as well as for remote communities in general. Reducing loads and using energy efficiently are given preference as these are low-cost energy solutions compared to building energy systems with intermittent RE resources. These energy solutions are also not so dependent on complex energy management systems and can conform with existing and future upgrades in the energy system of specific communities. Hence, they must all be given consideration when implementing energy transition strategies, especially in challenging contexts such as the Arctic regions. 


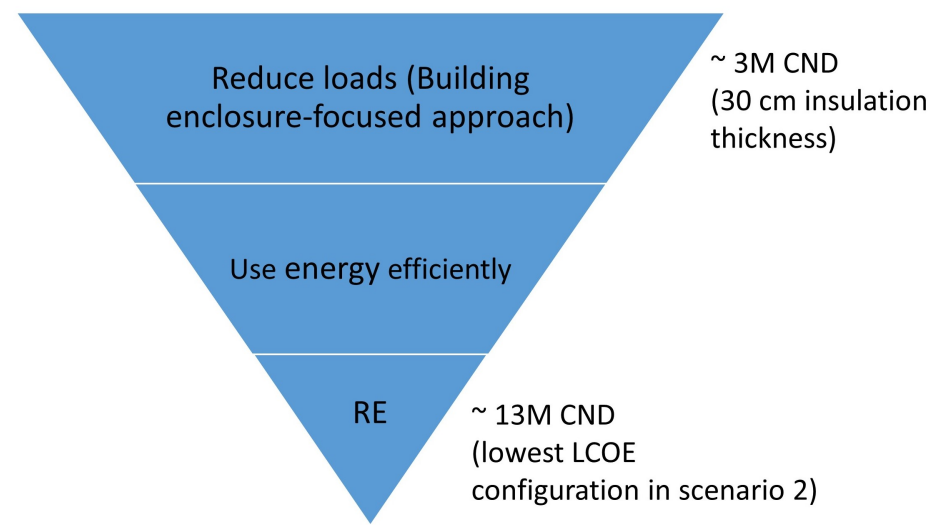

Figure 22: The inverted pyramid concept: How energy solutions should be prioritized (figure is adapted from RDH Consulting report [50.)

\subsection{Balancing the energy trilemma}

All of the energy solutions discussed so far in this work are key in holistically addressing energy challenges among Northern remote communities in order to maintain a reliable source of energy, ensure energy affordability, and to achieve deep decarbonization targets. The interplay between these goals can be quantified through the energy trilemma index model to assist decision makers. Huntington et al. [53] argued that the purpose of energy modeling is to produce insights and not just numbers. Hence, the formulated community-scale energy trilemma index model has value in its ability to powerfully communicate whether new policies are hindering or moving towards the desired position (in reference to the three axes) and what interwoven links between various stakeholders are needed to accelerate energy transitions for the community.

The method described in Section 2.4 was applied to scenario 2 as it yielded the best optimal results from the optimization process. In particular, the nine solutions of interest were assessed and the results are listed in Table 11 with the graphical representation shown in Fig. 23 The ranking process, the weightings applied, and the number of solutions evaluated in the Pareto front may vary depending on the insights and perspectives required from the energy model itself.

As depicted in Fig. 23, solutions 1 - 3 have excellent scores in terms of the energy security and energy affordability indicators. However, it performed poorly on the third dimension, energy sustainability. In contrast, solutions 6 - 9 yielded best results in terms of the sustainability axis but the increased RE capacities and the high costs involved for these solution sets, negatively impacted its overall trilemma score. In particular, the energy affordability indicators are preferable from the first three solutions mentioned previously. The solutions at the middle of the curve (solutions 4 - 6) seem to perform satisfactorily in all three dimensions but their average trilemma score is significantly lower than that of the first three solutions. Overall, solution 3 garnered the highest weighted average trilemma score of 73.33 in comparison with the other eight solutions of interest. However, its overall trilemma score can still be improved by testing new milestones or policies in reference to the energy sustainability indicators. For example, applying an appropriate price to carbon emissions [54 might be a suitable trajectory to address this issue. 


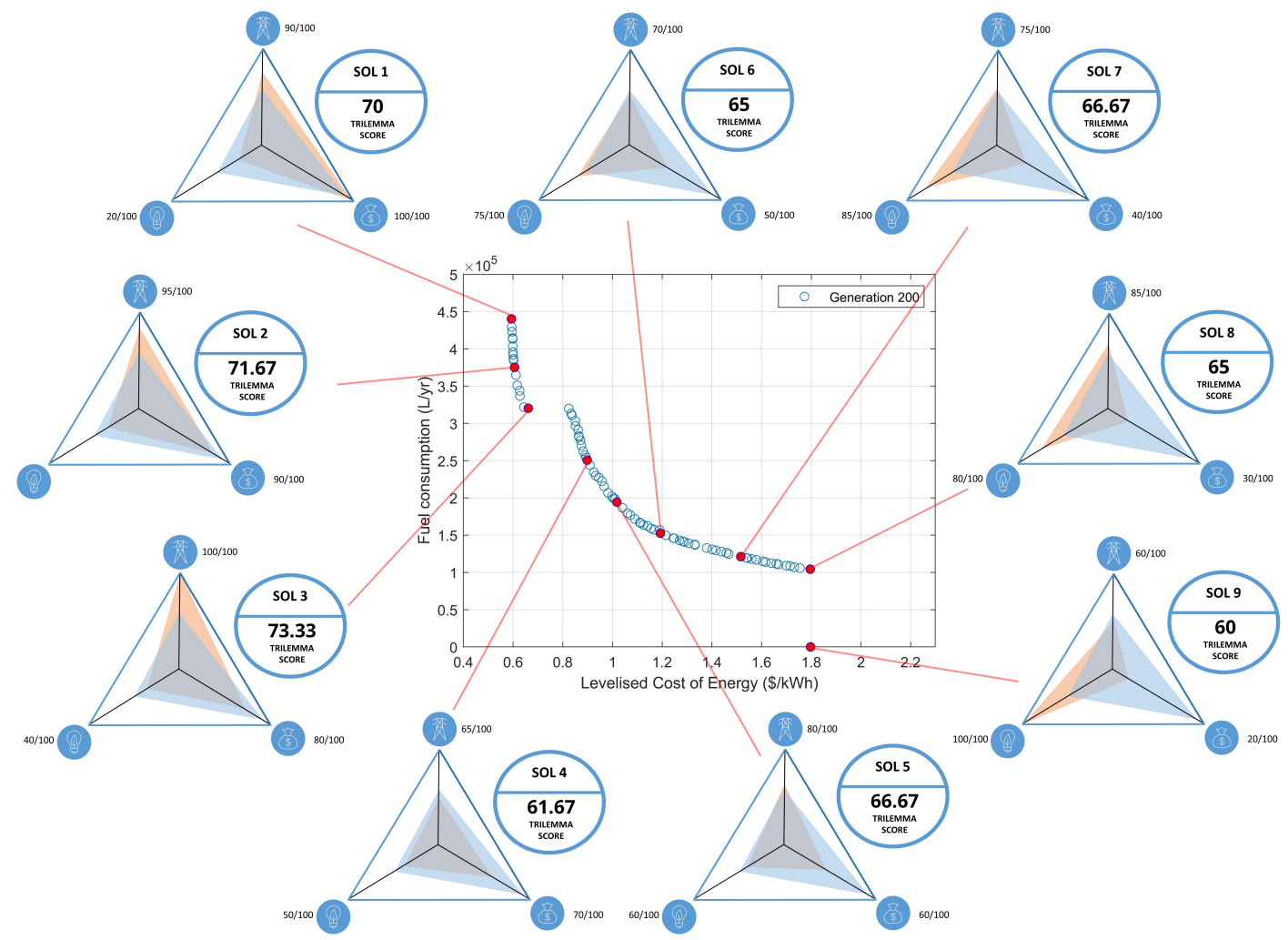

Figure 23: Energy trilemma index score (orange region) of scenario 2 overlaid on Canada's energy trilemma score (blue region).

Similar to the multi-objective optimization results discussed in Section 3.1, balancing the three dimensions of the energy trilemma involves trade-offs. Thus, one goal for the modeler is to analyze these trade-offs and translate these into policy insights.

\subsection{Results validation}

As this work involves modeling of complex engineering systems, it is important to compare the results of the MINES model to other validated energy modeling tools with similar characteristics. This validation approach has been lacking in other studies that involved energy system modeling.

In this work, the HOMER tool has been chosen to validate the results of MINES as it has been widely used and accepted in academia and industry (Section 1.1). Note that the respective model outputs cannot be compared directly, as HOMER employs single-objective optimization versus the multi-objective technique of this study. Instead, the simulation results were analyzed and compared. From Fig. 23, solution 1 has been selected and its configuration parameters were run in HOMER The tool delivered results (with percentage errors for each) as shown in Table 12 . This comparison shows consistent agreement across all parameters, and indicates successful validation of the optimization algorithm of the MINES model given the simulation and optimization algorithms are interlinked based on the modeling framework presented in Fig. 4. 


\section{Conclusions}

The results presented in this work have been shown to have significant value in holistically addressing multi-domain energy challenges and candidate solutions in Northern remote communities of Canada and beyond. This work examined the interplay between three energy modeling approaches, namely: (1) supply side design optimization of integrated energy systems with intermittent $\mathrm{RE}$ resources and $\mathrm{BT}$ storage; (2) demand side impacts of building enclosure-focused approach; (3) energy trilemma enabling a quantitative trade-off between results from the two approaches and understanding its impact with the energy trilemma index model.

A multi-objective modeling framework was applied in this study to evaluate the complex tradeoffs in designing integrated energy system. This technique offers comparison of a diversity of solutions between two conflicting design objectives to better support practitioners and policy makers. Based on the optimization results, a fully hybrid PV] [WT BT [DG [CONV] solution has been proposed. Multiple systems of this configuration were found to be viable according to the resulting Pareto front, but each solution is unique and has to be analyzed considering real-world applications.

Viable heating alternatives were also investigated. As compared with electric baseboard heaters, ASHP can reduce space heating load by up to 40\%. However, load fluctuations from the hourly variation of the heat pump's $C O P$ as influenced by the outside temperature were observed to negatively impact the overall performance of the energy system. In particular, this resulted in larger BT storage capacity components. The increase in BT storage was also found to be greatly affected by the peak load of the community. The constraints formulation, objective functions, and the discrete decision variables also influenced this result.

In conjunction with the previously mentioned optimization results, methods for improving building performance such as installation of MVHR maximizing air-tightness, and optimizing building enclosures were also evaluated in the MINES model. Varying building enclosure characteristics (from normal to passive) were found to produce the highest building performance by reducing the space heating load by about $40 \%$ annually as compared with the other two methods pointed out earlier. Hence, it has been applied in the scenarios run in the model. The building enclosure-focused approach also offers non-energy benefits such as thermal comfort and increased resiliency in extreme temperature events and power outages.

Lastly, incorporating the results from the design space optimization and the impact of utilizing high-performance building enclosures provides a vast range of energy solutions for communities in Northern Canada. However, determination of which energy solutions to prioritize should also be considered in the decision making process of the community. Central to this aspect is the formulation of the community-scale energy trilemma index model. This tool processes the results from the MINES model, and quantifies various stakeholders' viewpoints by balancing the dimensions of the energy trilemma. For example, solution 3 from scenario 2 achieved the highest trilemma score of 73.33 in comparison with the other eight solutions of interest. It was highlighted that this weighted average trilemma score can still be improved by testing new milestones and policies affecting the energy situation of the community. 


\section{Future work}

The authors are working with WWF to come up with a more comprehensive study on energy efficiency initiatives in the North. This future work is on-going and data are now being collected from the installed energy monitoring devices from the community of Gjoa Haven in Nunavut. This will be part of a bigger project for the establishment of the first Inuit energy cooperative in the Northern territories of Canada. Also, the MINES model will be further developed by including a stochastic module that will account for uncertainties caused by the renewables and other parameters in the model.

\section{Acknowledgement}

Funding for this work was provided by Polar Knowledge Canada and the Marine Environmental Observation, Prediction and Response Network (MEOPAR). Authors would also like to acknowledge support from the Government of Northwest Territories and Northwest Territories Power Corporation by providing actual electrical load and wind data which served as vital inputs for the project. Significant part of this work has been conducted at the Center for Renewable Energy Systems Technology (CREST) at Loughbrough University, UK as funded by MITACS and MEOPAR.

\section{Appendix A. Overview of technology input parameters in the model}

This appendix provides an overview of some of the input parameters used in the MINES model. To ensure accuracy of the assumptions made in this work, the data were gathered in coordination with the Northwest Territories Power Corporation (NTPC) and the local government of the NWT

\section{References}

[1] D. Cherniak, V. Dufresne, L. Keyte, A. Mallett, S. Schott, Report on the State of Alternative Energy in the Arctic, Technical Report September, 2015.

[2] B. Gilmour, E. Oldfield, H. Platis, E. Wicks, Toward a positive energy future in Northern and remote communities, Technical Report, 2018.

[3] Government of Canada (National Energy Board), Market Snapshot: Explaining the high cost of power in northern Canada, 2017. URL: https://www.neb-one.gc.ca/nrg/ntgrtd/mrkt/ snpsht/2017/02-03hghcstpwr-eng.html?=undef ined $\{\&\}$ wbdisable=true

[4] G. Poelzer, G. H. Gjorv, G. Holdmann, N. Johnson, B. M. Magnusson, L. Sokka, M. Tsyiachiniouk, S. Yu, Developing Renewable Energy in Arctic and Sub-Arctic Regions and Communities (2016) 1-68. 
[5] High Commission of Canada in the United Kingdom, The Canadian Arctic, 2018. URL: https://www.canadainternational.gc.ca/united\{_\}kingdom-royaume\{_\}uni/ bilateral\{_\}relations\{_\}bilaterales/arctic-arctique.aspx?lang=eng.

[6] Natural Resources Canada, Indigenous Off-diesel Initiative, 2020. URL: https://impact. canada.ca/en/challenges/off-diesel.

[7] Canada Energy Regulator, Market Snapshot: Fuel poverty across Canada - lower energy efficiency in lower income households, 2017. URL: https://www.cer-rec.gc.ca/nrg/ntgrtd/ mrkt/snpsht/2017/08-05flpvrt-eng.html?=undefined $\{\&\}$ wbdisable=true.

[8] B. Kentish, Arctic is warming at twice the rate of the rest of the planet, scientists warn, 2017. URL: https://www.independent.co.uk/environment/ arctic-warming-twice-rate-rest-of-planet-global-warming-snow-water-ice-perma:rost-arctic-m html.

[9] The Narwhal, How can Canada's North get off diesel?, 2019. URL: https://thenarwhal.ca/ how-canadas-north-get-off-diesel/

[10] I. Das, C. Canizares, Renewable Energy Deployment in Canadian Arctic - Phase I (PreFeasibility studies and community engagement report for Nunavut), Technical Report, World Wildlife Fund, Waterloo Institute for Sustainable Energy, 2016.

[11] HOMER Energy, HOMER Pro, 2019. URL: https://www.homerenergy.com/products/pro/ index.html.

[12] L. Tribioli, R. Cozzolino, L. Evangelisti, G. Bella, Energy management of an off-grid hybrid power plant with multiple energy storage systems, Energies 9 (2016).

[13] I. Das, C. Canizares, Fuelling change in the arctic - Phase II (Feasibility studies on selected communities of Nunavut and Northwest Territories), Technical Report, World Wildlife Fund, Waterloo Institute for Sustainable Energy, 2016.

[14] H. Sugihara, J. Komoto, K. Tsuji, A multi-objective optimization model for determining urban energy systems under integrated energy service in a specific area, Electrical Engineering in Japan (English translation of Denki Gakkai Ronbunshi) 147 (2004) 20-31.

[15] E. Lo Cascio, D. Borelli, F. Devia, C. Schenone, Future distributed generation: An operational multi-objective optimization model for integrated small scale urban electrical, thermal and gas grids, Energy Conversion and Management 143 (2017) 348-359.

[16] K. Orehounig, R. Evins, V. Dorer, Integration of decentralized energy systems in neighbourhoods using the energy hub approach, Applied Energy 154 (2015) 277-289.

[17] L. Cabrol, P. Rowley, Towards low carbon homes - A simulation analysis of building-integrated air-source heat pump systems, Energy \& Buildings 48 (2012) 127-136. 
[18] R. Renaldi, A. Kiprakis, D. Friedrich, An optimisation framework for thermal energy storage integration in a residential heat pump heating system, Applied Energy 186 (2017) 520-529.

[19] M. R. Quitoras, P. E. Campana, C. Crawford, Exploring electricity generation alternatives for Canadian Arctic communities using a multi-objective genetic algorithm approach, Energy Conversion and Management 210 (2020) 112471.

[20] Standing Senate Committee on Energy Environment and Natural Resources, Powering Canada's Territories, Technical Report, 2014.

[21] Government of Northwest Territories, Northwest Territories Energy Report, Technical Report May, 2011.

[22] World Wildlife Fund Canada, Renewble energy in Nunavut (Scoping Analysis), Technical Report, 2019.

[23] L. H. Anh, L. S. Dong, V. Kreinovich, N. N. Thach, Econometrics for Financial Applications, Springer Nature, 2018.

[24] K. Deb, A. Member, A. Pratap, S. Agarwal, T. Meyarivan, A fast and elitist multi-objective genetic algorithm:NSGAII 6 (2002) 182-197.

[25] R. Evins, P. Pointer, R. Vaidyanathan, S. Burgess, A case study exploring regulated energy use in domestic buildings using design-of-experiments and multi-objective optimisation, Building and Environment 54 (2012) 126-136.

[26] J. Forde, C. J. Hopfe, R. S. McLeod, R. Evins, Temporal optimization for affordable and resilient Passivhaus dwellings in the social housing sector, Applied Energy 261 (2020) 114383.

[27] J. J. Roberts, A. Marotta Cassula, J. L. Silveira, E. da Costa Bortoni, A. Z. Mendiburu, Robust multi-objective optimization of a renewable based hybrid power system, Applied Energy 223 (2018) 52-68.

[28] Y. Zhang, A. Lundblad, P. Elia, F. Benavente, J. Yan, Battery sizing and rule-based operation of grid-connected photovoltaic-battery system : A case study in Sweden Level of Confidence State of Charge, Energy Conversion and Management 133 (2017) 249-263.

[29] M. A. Marin, Long-Term Renewable Energy Generation Planning for Off-grid Remote Communities, Ph.D. thesis, University of Waterloo, 2015.

[30] P. E. Campana, S. J. Quan, F. I. Robbio, A. Lundblad, Y. Zhang, T. Ma, B. Karlsson, J. Yan, Optimization of a residential district with special consideration on energy and water reliability, Applied Energy 194 (2016) 751-764.

[31] Government of Northwest Territories, 2012 Northwest Territories Energy Charrette, Technical Report January, 2013. 
[32] M. R. D. Quitoras, M. L. S. Abundo, L. A. M. Danao, A techno-economic assessment of wave energy resources in the Philippines, Renewable and Sustainable Energy Reviews 88 (2018) $68-81$.

[33] M. Sharafi, T. Y. Elmekkawy, Multi-objective optimal design of hybrid renewable energy systems using PSO-simulation based approach 68 (2014).

[34] M. Matthew, Assessing the operational robustness of the HOMER model for Marine Corps use in expeditionary environments, Ph.D. thesis, Naval Postgraduate School, 2014.

[35] E. J. Hoevenaars, C. A. Crawford, Implications of temporal resolution for modeling renewables-based power systems, Renewable Energy 41 (2012) 285-293.

[36] HOMER Pro 3.13, Fuel Consumption Data, 2020. URL: https://www.homerenergy.com/ products/pro/docs/latest/fuel\{_\}curve.html.

[37] B. S. Borowy, Z. M. Salameh, Methodology for optimally sizing the combination of a battery bank and PV array in a Wind/PV hybrid system, IEEE Transactions on Energy Conversion 11 (1996) 367-373.

[38] T. Tezer, R. Yaman, G. Yaman, Evaluation of approaches used for optimization of standalone hybrid renewable energy systems, Renewable and Sustainable Energy Reviews 73 (2017) $840-853$.

[39] R. Hendron, J. Burch, Development of standardized domestic hot water event schedules for residential buildings, Proceedings of the Energy Sustainability Conference 2007 (2007) $531-540$.

[40] Arctic Energy Alliance, Sachas Harbour Energy Profile, Technical Report, 2008. doi:10.1351/ goldbook.e02112

[41] World Energy Council, World Energy Trilemma Index — 2017, Technical Report, 2017.

[42] ARUP, Five-minute guide: Energy trilemma (2019).

[43] NWT Bureau of Statistics, Housing Indicators, Technical Report, 2019.

[44] Government of Northwest Territories, NWT Climate Change Impacts and Adaptation Report, Technical Report, 2008. URL: Www.enr.gov.nt.ca/\{_\}live/documents/content/

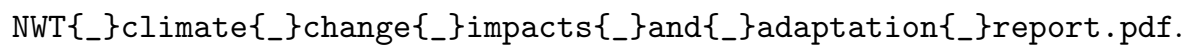

[45] Arctic Heat Pumps, Arctic Cold Climate Heat Pumps, 2019. URL: https://www. arcticheatpumps.com/.

[46] M. Pavičević, T. Novosel, T. Pukšec, N. Duić, Hourly optimization and sizing of district heating systems considering building refurbishment - Case study for the city of Zagreb, Energy 137 (2017) 1264-1276. 
[47] CanmetENERGY, Energy Policy Context and Market Characterization for the Development of a Northern Communities Energy Technology Intervention Strategy, Technical Report September, 2015.

[48] Energy Efficiency, Canadian Provincial Energy Efficiency Scoreboard, 2019. URL: http:// www.efficiencycanada.org/.

[49] T.-P. Frappé-Sénéclauze, D. Heerema, . Karen, T. Wu, Accelerating Market Transformation for High-Performance Building Enclosures (2016).

[50] RDH Building Engineering Ltd., Window Design for Canada's North, Technical Report, 2016.

[51] E. Burrell, What is Mechanical Ventilation with Heat Recovery (MVHR)?, 2015. URL: https: //elrondburrell.com/blog/passivhaus-mechanical-ventilation-heat-recovery/.

[52] M. Jakob, Marginal costs and co-benefits of energy efficiency investments. The case of the Swiss residential sector, Energy Policy 34 (2006) 172-187.

[53] J. L. Sweeney, Modeling for Insights, not Numbers : the Experiences of the Energy Modeling Forum 1, OMEGA 10 (1982) 449-462.

[54] Government of the Northwest Territories, Implementing Pan-Canadian Carbon Pricing in the Northwest Territories, Technical Report July, 2017. 


\begin{tabular}{|c|c|c|c|}
\hline \multicolumn{4}{|c|}{ Nomenclature } \\
\hline ASHP & Air-source Heat Pump & $H G$ & Heat gain \\
\hline BT & Battery & $H L$ & Heat losses \\
\hline $\operatorname{CCOS}$ & Cycle Charging Operation Strategy & $H L_{i}$ & Heat losses due to infiltration \\
\hline CONV & Converter & $H L_{t}$ & Heat losses due to transmission \\
\hline DG & Diesel Generator & $H L_{v}$ & Heat losses due to ventilation \\
\hline DHW I & Domestic Hot Water & $i$ & System component \\
\hline GA & Genetic Algorithm & $L C C$ & Life Cycle Cost \\
\hline HOMER & $\begin{array}{l}\text { R Hybrid Optimization of Multiple } \\
\text { Energy Resources }\end{array}$ & $\begin{array}{l}\angle C O E \\
L P S P \text { I }\end{array}$ & Loss of Power Supply Probability \\
\hline HRES I & Hybrid Renewable Energy System & $M$ & Mass of the building \\
\hline LFOS I & Load Following Operation Strategy & $n$ & Life of the energy system in years \\
\hline MINES & $\begin{array}{l}\text { Sulti-objective INtegrated Energy } \\
\text { System }\end{array}$ & $N P C$ & Net Present Cost \\
\hline MVHR & Mechanical Ventilation with Heat Re- & $O \& M$ & Operations and maintenance costs \\
\hline & covery & $P_{b a t t}$ & Energy stored in the BT \\
\hline NSGA-I & -II Non-dominated Sorting Genetic Al- & $P_{\text {deficit }}$ & Power deficit from all power sources \\
\hline & gorithm - II & $P_{D G, r}$ & Rated capacity of DG \\
\hline NTPC & Northwest Territories Power Corpora- & $P_{D G}$ & Power produced by DG \\
\hline & tion & $P_{\text {excess }}$ & Excess electricity \\
\hline NWT I & Northwest Territories & $P_{g e n}$ & Overall power generated from the sys- \\
\hline PV & Photovoltaic & & 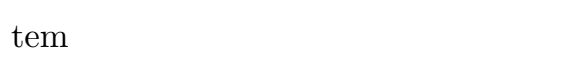 \\
\hline $\mathrm{RE}$ & Renewable Energy & $P_{R E}$ & Power produced by RE \\
\hline SHGC & Solar Heat Gain Coefficient & $Q_{d h w}$ & Daily average demand for DHW \\
\hline WEC & World Energy Council & $Q_{s h}$ & Thermal energy demand for space \\
\hline WT & Wind Turbine & & heating \\
\hline WWF & World Wildlife Fund & r & Discount rate \\
\hline WWR & Windows-to-wall ratio & $R E_{\text {pen }}[1$ & $\mathrm{RE}$ penetration \\
\hline$\alpha_{h r}$ & Heat recovery efficiency & $S$ & Salvage value \\
\hline$\eta_{i}$ & Infiltration air changes per hour & $S O C$ & State of charge of the battery \\
\hline$\eta_{v}$ & Ventilation air changes per hour & $S O C_{s p}$ & Set point state of charge \\
\hline$\rho_{w}$ & Water density & $t$ & Time \\
\hline$A_{b}$ & Total surface area of the building & $T_{i n}$ & Set indoor temperature \\
\hline$c_{p, a}$ & Air specific heat & $35 T^{T_{\text {out }}}$ & Outdoor temperature \\
\hline$c_{p, b}$ & Building heat specific capacity & $T_{w, c}$ & Cold water temperature \\
\hline$c_{p, w}$ & Water specific heat & & Hot water temperature \\
\hline
\end{tabular}


Table 1: GA configuration parameters.

\begin{tabular}{ll}
\hline Parameter & Description \\
\hline Algorithm & Variant of NSGA-II [24] \\
Generations & 200 \\
Population & 100 \\
Crossover function & Heuristic \\
Crossover rate(\%) & 90 \\
Mutation function & Non-uniform \\
Tournament size & 2 \\
\hline
\end{tabular}

Table 2: Dimension of the discrete variables in the optimization algorithm.

\begin{tabular}{|c|c|}
\hline Parameter & Value \\
\hline WT quantity & $0-500$ \\
\hline WT capacity $(\mathrm{kW})$ & $95,95,100,100$ \\
\hline PV quantity & $0-500$ \\
\hline PV capacity $(\mathrm{kW})$ & $15,25,20,25.025$ \\
\hline BT quantity & $0-500$ \\
\hline BT capacity (kWh ) & $55,13.9,7.37,9.24$ \\
\hline DG quantity & $0-100$ \\
\hline DG capacity $(\mathrm{kW})$ & $300,320,225,150$ \\
\hline CONV quantity & $0-10$ \\
\hline CONV capacity $(\mathrm{kW})$ & $200,250,270,300$ \\
\hline Operation strategy & LFOS and CCOS \\
\hline
\end{tabular}

Table 3: Building simulation parameters to estimate heat load requirement of the community.

\begin{tabular}{ll}
\hline Parameter & Value \\
\hline$U\left(\mathrm{~W} / \mathrm{m}^{2}-\mathrm{K}\right)$ & 0.5 \\
\hline$T_{i n}\left({ }^{\circ} \mathrm{C}\right)$ & 18 \\
\hline \hline$\alpha_{h r}(\%)$ & 0 \\
\hline \hline$\eta_{v}(1 / \mathrm{h})$ & 0.4 \\
\hline \hline$\eta_{i}(1 / \mathrm{h})$ & 0.4 \\
\hline \hline $\mathrm{SHGC}(\%)$ & 50 \\
\hline \hline $\mathrm{WWR}(\%)$ & 50 \\
\hline
\end{tabular}


Table 4: Community-scale energy trilemma index structure; the equal weightings represent the three axes of the energy trilemma as equally important and cannot be treated independently.

\begin{tabular}{|c|c|c|}
\hline Indicator category & Parameter & Weight \\
\hline \multirow{2}{*}{ Energy Security } & $L P S P$ & $16.67 \%$ \\
\hline & $P_{\text {excess }}$ & $16.67 \%$ \\
\hline \multirow{2}{*}{ Energy Equity } & $L C C$ & $16.67 \%$ \\
\hline & $\angle C O E$ & $16.67 \%$ \\
\hline \multirow{2}{*}{ Environmental Sustainability } & $\mathrm{CO}_{2 \text { emissions, life cycle }}$ & $16.67 \%$ \\
\hline & \begin{tabular}{|l|l|}
$R E_{\text {pen }}$ & \\
\end{tabular} & $16.67 \%$ \\
\hline
\end{tabular}

Table 5: Rank and scoring table for the energy trilemma considering nine solutions of interest.

\begin{tabular}{|c|c|c|c|c|c|c|c|c|c|}
\hline Rank & 1 & 2 & 3 & 4 & 5 & 6 & 7 & 8 & 9 \\
\hline Score & 100 & 90 & 80 & 70 & 60 & 50 & 40 & 30 & 20 \\
\hline
\end{tabular}


Table 6: Configuration characteristics of the three solutions of interest determined from the Pareto front of Scenario 1.

\begin{tabular}{|c|c|c|c|c|}
\hline \multirow{3}{*}{ Parameter } & \multirow{3}{*}{ Unit } & \multicolumn{3}{|c|}{ Optimization results } \\
\hline & & Min. $L C O E$ and & Trade-off Point & Max. LCOE and \\
\hline & & Max. fuel fons $_{\text {. }}$ & & Min. fuel cons \\
\hline $\mathrm{PV}$ & $\mathrm{kW}$ & $650(25 \mathrm{~kW} \times 26)$ & $2,575(25 \mathrm{~kW} \times 103)$ & - \\
\hline WT & $\mathrm{kW}$ & $855(95 \mathrm{~kW} \times 9)$ & $1,235(95 \mathrm{~kW} \times 13)$ & $5,225(95 \mathrm{~kW} \times 55)$ \\
\hline \multirow[t]{2}{*}{$\mathrm{BT}$} & $\mathrm{kWh}$ & $4,620 \quad(9.24 \mathrm{kWh} \quad \mathrm{x}$ & $14,410 \quad(55 \mathrm{kWh} \quad \mathrm{x}$ & $14,630 \quad(55 \mathrm{kWh} \quad \mathrm{x}$ \\
\hline & & $500)$ & 262) & 266) \\
\hline $\mathrm{DG}$ & $\mathrm{kW}$ & $1,125(225 \mathrm{~kW} \times 5)$ & $1,125(225 \mathrm{~kW} \times 5)$ & - \\
\hline CONV & $\mathrm{kW}$ & $1,000(200 \mathrm{~kW} \times 5)$ & $1,200(200 \mathrm{~kW} \times 6)$ & $1,200(200 \mathrm{~kW} \times 6)$ \\
\hline Operation Strategy & - & LFOS & LFOS & LFOS \\
\hline$P_{p v}$ & $\mathrm{kWh}$ & 506,499 & $2,097,521$ & - \\
\hline$P_{w}$ & $\mathrm{kWh}$ & $2,456,400$ & $5,322,200$ & $22,517,001$ \\
\hline$P_{B T, \text { discharge }}$ & $\mathrm{kWh}$ & 150,143 & 656,701 & 825,357 \\
\hline$P_{D G}$ & $\mathrm{kWh}$ & $1,252,981$ & 971,224 & - \\
\hline$L P S P$ & $\%$ & 0 & 0 & 0 \\
\hline$R E_{\text {pen }}$ & $\%$ & 68.11 & 88.43 & 100 \\
\hline$P_{\text {excess }}$ & $\%$ & 16.58 & 4.92 & 1.14 \\
\hline fuel $_{\text {cons }}$ & $\mathrm{L} / \mathrm{yr}$ & 676,792 & 329,856 & - \\
\hline $\mathrm{CO}_{2}$ emissions, life cycle & $\mathrm{tCO}_{2-\mathrm{eq}} / \mathrm{yr}$ & 3,076 & 2,692 & 1,371 \\
\hline$C C$ & $\mathrm{CND} \$$ & $22,873,000$ & $51,822,100$ & $120,575,000$ \\
\hline \multirow[t]{2}{*}{$L C O E$} & CND & 0.627133 & 1.12129 & 1.989 \\
\hline & $\$ / \mathrm{kWh}$ & & & \\
\hline$L C C$ & $\mathrm{CND} \$$ & $55,576,000$ & $99,368,000$ & $176,263,000$ \\
\hline
\end{tabular}


Table 7: Comparison of optimal configuration of the system with and without the heat load.

\begin{tabular}{|c|c|c|c|}
\hline \multirow{4}{*}{ Parameter } & \multirow{4}{*}{ Unit } & \multicolumn{2}{|c|}{ Optimization results } \\
\hline & & Case 1: $\quad$ Min. & Case 2: $\quad$ Min. \\
\hline & & $L C O E$ (Elec and & $L C O E$ (Elec Only) \\
\hline & & \multicolumn{2}{|l|}{ Heat) } \\
\hline $\mathrm{PV}$ & $\mathrm{kW}$ & $650(25 \mathrm{~kW} \times 26)$ & $100(25 \mathrm{~kW} \times 4)$ \\
\hline WT & $\mathrm{kW}$ & $855(95 \mathrm{~kW} \times 9)$ & $190(95 \mathrm{~kW} \times 2)$ \\
\hline \multirow[t]{2}{*}{$\mathrm{BT}$} & \multirow[t]{2}{*}{$\mathrm{kWh}$} & $4,620 \quad(9.24 \mathrm{kWh} \quad \mathrm{x}$ & \multirow{2}{*}{$\begin{array}{l}4,481.4(9.24 \mathrm{kWh} \mathrm{x} \\
485)\end{array}$} \\
\hline & & 500) & \\
\hline $\mathrm{DG}$ & $\mathrm{kW}$ & $1,125(225 \mathrm{~kW} \times 5)$ & $225(225 \mathrm{~kW} \times 1)$ \\
\hline $\mathrm{CONV}$ & $\mathrm{kW}$ & $1,000(200 \mathrm{~kW} \times 5)$ & $250(250 \mathrm{~kW} \times 1)$ \\
\hline Operation Strategy & - & LFOS & $\mathrm{CCOS}$ \\
\hline$P_{p v}$ & $\mathrm{kWh}$ & 506,499 & 81,457 \\
\hline$P_{w}$ & $\mathrm{kWh}$ & $2,456,400$ & 818,800 \\
\hline$P_{B T, \text { discharge }}$ & $\mathrm{kWh}$ & 150,143 & 396,062 \\
\hline \begin{tabular}{l|l}
$P_{D G}$ & \\
\end{tabular} & $\mathrm{kWh}$ & $1,252,981$ & 356,400 \\
\hline$L P S P$ & $\%$ & 0 & 0 \\
\hline$R E_{\text {pen }}$ & $\%$ & 68.11 & 71.64 \\
\hline$P_{\text {excess }}$ & $\%$ & 16.58 & 9.14 \\
\hline fuel $_{\text {cons }}$ & $\mathrm{L} / \mathrm{yr}$ & 676,792 & 116,703 \\
\hline $\mathrm{CO}_{2}$ emissions, life cycle & $\mathrm{tCO}_{2-\mathrm{eq}} / \mathrm{yr}$ & 3,076 & 770 \\
\hline \begin{tabular}{|l|l|}
$C C$ \\
\end{tabular} & $\mathrm{CND} \$$ & $22,873,000$ & $5,023,520$ \\
\hline \multirow[t]{2}{*}{$L C O E$} & CND & 0.627133 & 0.522406 \\
\hline & $\$ / \mathrm{kWh}$ & & \\
\hline$L C C$ & CND $\$$ & $55,576,000$ & $9,580,800$ \\
\hline
\end{tabular}


Table 8: Scenarios implemented in the MINES model.

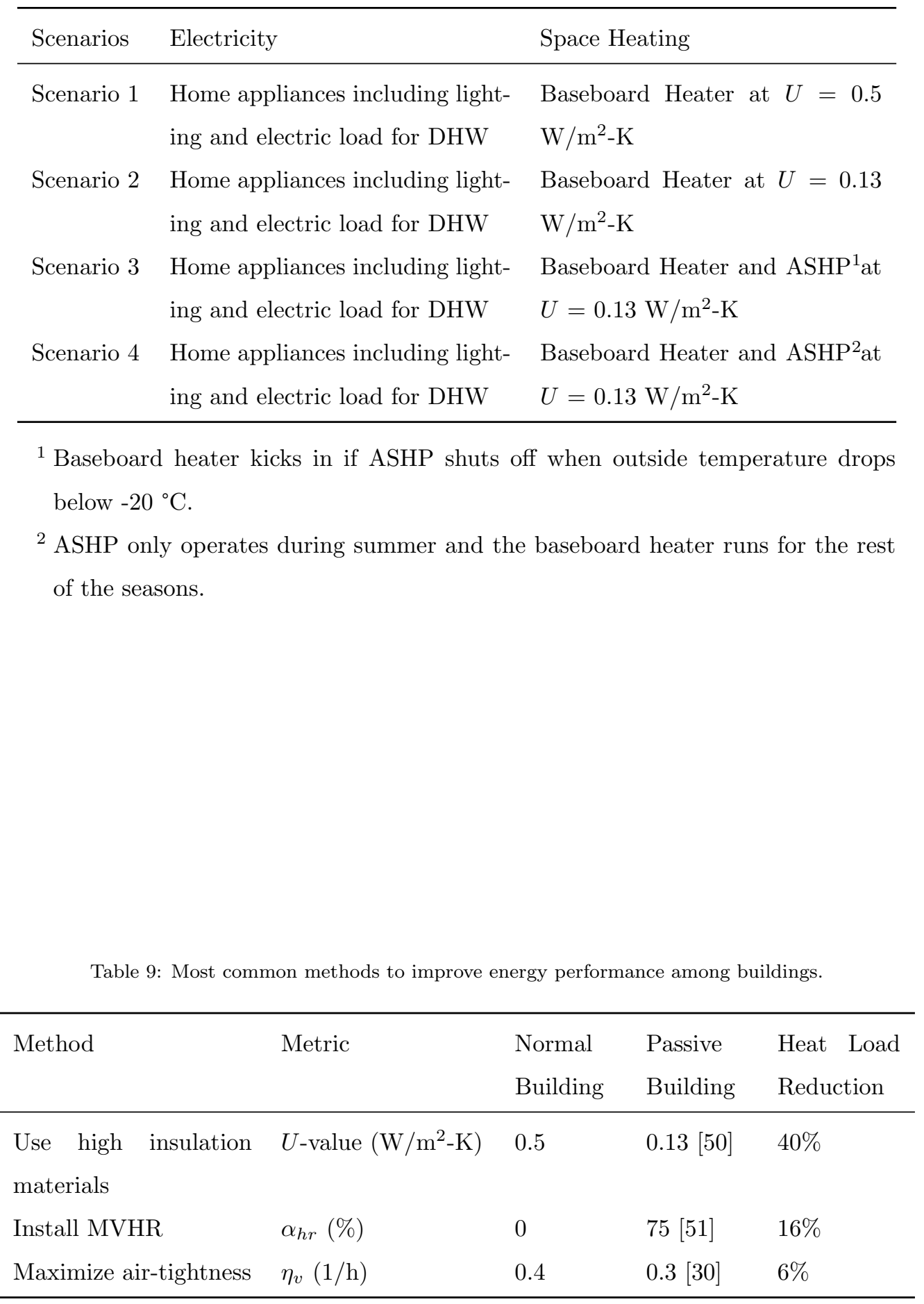


Table 10: Investment costs invoved in building enclosure improvements 52 .

\begin{tabular}{|c|c|c|c|}
\hline \multirow{2}{*}{ Insulation thickness (Тype) ${ }^{1}$} & \multirow{2}{*}{$\mathrm{U}_{\text {-value }}{ }^{2}$} & \multicolumn{2}{|c|}{ Investment costs ${ }^{4}\left(\mathrm{CND} \$ / \mathrm{m}^{2}\right)$} \\
\hline & & Mean $^{3}$ & Best practice \\
\hline $30 \mathrm{~cm}(\mathrm{~N})$ & 0.15 & 407.31 & 334.74 \\
\hline $20 \mathrm{~cm}(\mathrm{~N})$ & 0.20 & 327.72 & 311.34 \\
\hline $16 \mathrm{~cm}(\mathrm{~N})$ & 0.23 & 297.29 & 278.56 \\
\hline $12 \mathrm{~cm}(\mathrm{ER})$ & 0.28 & 273.88 & 262.18 \\
\hline $0 \mathrm{~cm}(\mathrm{M})$ & $0.85-1.1$ & 81.93 & 81.93 \\
\hline
\end{tabular}

${ }^{1} \mathrm{~N}$ (New buildings); M (Maintenance of existing buildings - plaster repairs, facade coating); ER (Energy efficiency refurbishment)

${ }^{2} \mathrm{~W} / \mathrm{m}^{2}-\mathrm{K}$

${ }^{3}$ Mean value from surveyed companies

4 The present value (year 2020) of the investment costs were calculated using an inflation rate of 3.5\% from 2004 (study from Jakob [52]).

Table 11: Rank and scoring table of the community-scale energy trilemma index model relative to the 9 solutions of interest (can be adjusted by the modeler) in the Pareto front.

\begin{tabular}{cccccc}
\hline Solution & Security & Affordability & Sustainability & Overall Score & Rank \\
\hline 1 & 90 & 100 & 20 & 70 & 3 \\
2 & 95 & 90 & 30 & 71.67 & 2 \\
$\mathbf{3}$ & $\mathbf{1 0 0}$ & $\mathbf{8 0}$ & $\mathbf{4 0}$ & $\mathbf{7 3 . 3 3}$ & $\mathbf{1}$ \\
4 & 65 & 70 & 50 & 61.67 & 8 \\
5 & 80 & 60 & 60 & 66.67 & 4 \\
6 & 70 & 50 & 75 & 65 & 6 \\
7 & 75 & 40 & 85 & 66.67 & 4 \\
8 & 85 & 30 & 80 & 65 & 6 \\
9 & 60 & 20 & 100 & 60 & 9 \\
\hline
\end{tabular}


Table 12: Validation of simulation results with HOMER.

\begin{tabular}{|c|c|c|c|c|}
\hline \multirow{2}{*}{ Parameter } & \multirow{2}{*}{ Unit } & \multicolumn{3}{|c|}{ Simulation results } \\
\hline & & HOMER & MINES & $\%$ Error \\
\hline$P_{p v}$ & $\mathrm{kWh}$ & 506,195 & 506,498 & $0.06 \%$ \\
\hline$P_{w}$ & $\mathrm{kWh}$ & $2,475,542$ & $2,456,400$ & $0.78 \%$ \\
\hline$P_{D G}$ & $\mathrm{kWh}$ & $1,244,238$ & $1,252,891$ & $0.70 \%$ \\
\hline $\overrightarrow{S O C}$ & $\%$ & 554,923 & 551,087 & $0.70 \%$ \\
\hline$C C$ & $\mathrm{CND} \$$ & $15,417,200$ & $15,417,200$ & $0 \%$ \\
\hline$L C O E$ & $\mathrm{CND} \$ / \mathrm{kWh}$ & 0.6139 & 0.5932 & $3.36 \%$ \\
\hline$L C C$ & $\mathrm{CND} \$$ & $36,965,330$ & $35,721,900$ & $3.36 \%$ \\
\hline
\end{tabular}

${ }^{1}$ For the sake of comparison, $S O C$ per timestep was summed up for one whole year and compared to HOMER.

Table A.13: Solar PV parameters used in the simulation.

\begin{tabular}{llllll}
\hline \multirow{2}{*}{ Parameter } & Unit & \multicolumn{5}{c}{ Values per technology type } \\
\cline { 3 - 5 } & & 1 & 2 & 3 & 4 \\
\hline Manufacturer & - & Generic & Schneider & Schneider & Huawei \\
\multicolumn{1}{l}{} & & & Electric & Electric \\
$Y_{p v}$ & $\mathrm{~kW}$ & 15 & 25 & 20 & 25.025 \\
\hline \hline$f_{p v}$ & $\%$ & 80 & 85 & 85 & 96 \\
\hline \hline$\alpha_{p}$ & $\% /{ }^{\circ} \mathrm{C}$ & -0.44 & -0.41 & -0.41 & -0.41 \\
\hline$\eta_{m p, S T C}$ & $\%$ & 14.70 & 17.30 & 17.30 & 17.30 \\
Lifetime & years & 10 & 25 & 25 & 25 \\
\hline
\end{tabular}

Table A.14: Wind turbine parameters used in the simulation.

\begin{tabular}{llllll}
\hline \multirow{2}{*}{ Parameter } & Unit & \multicolumn{4}{c}{ Values per technology type } \\
\cline { 3 - 5 } & & 1 & 2 & 3 & 4 \\
\hline Manufacturer & - & XANT & Northern & XANT & Northern \\
Rated power & $\mathrm{kW}$ & 95 & 95 & 100 & Power \\
Hub height & $\mathrm{m}$ & 38 & 37 & 31.8 & 30 \\
Lifetime & years & 20 & 20 & 20 & 20 \\
\hline
\end{tabular}


Table A.15: Battery storage parameters used in the simulation.

\begin{tabular}{|c|c|c|c|c|c|}
\hline \multirow{2}{*}{ Parameter } & \multirow{2}{*}{ Unit } & \multicolumn{4}{|c|}{ Values per technology type } \\
\hline & & 1 & 2 & 3 & 4 \\
\hline Manufacturer & - & Generic & Rolls/Surrette & $\begin{array}{l}\text { BAE Batte- } \\
\text { rien GmbH }\end{array}$ & $\begin{array}{l}\text { BAE Batte- } \\
\text { rien GmbH }\end{array}$ \\
\hline Nominal capacity & $\mathrm{kWh}$ & 55 & 13.9 & 7.37 & 9.24 \\
\hline Nominal voltage & $\mathrm{V}$ & 720 & 2 & 2 & 2 \\
\hline$q_{\max }$ & $\mathrm{Ah}$ & 76.4 & 6950 & 3.68 & 4620 \\
\hline$c_{B T}$ & - & 0.927 & 0.267 & 0.369 & 0.355 \\
\hline$k_{B T}$ & $1 / \mathrm{h}$ & 0.989 & 0.385 & 0.832 & 0.869 \\
\hline Roundtrip \% & $\%$ & 97 & 80 & 90 & 90 \\
\hline$S O C_{\min }$ & $\%$ & 30 & 30 & 30 & 30 \\
\hline$Q_{\text {thrpt }}$ & $\mathrm{kWh} / \mathrm{yr}$ & 240,000 & $19,434.10$ & 7,728 & 9,744 \\
\hline$R_{B T, f}$ & years & 20 & 20 & 20 & 20 \\
\hline
\end{tabular}

Table A.16: Diesel generator parameters used in the simulation.

\begin{tabular}{llllll}
\hline \multirow{2}{*}{ Parameter } & Unit & \multicolumn{5}{c}{ Values per technology type } \\
\cline { 3 - 6 } & & 1 & 2 & 3 & 4 \\
\hline Manufacturer & - & Generic & Generic & Generic & Generic \\
Rated capacity & $\mathrm{kWh}$ & 300 & 320 & 225 & 150 \\
\hline$F_{0}$ & $\mathrm{~L} / \mathrm{h} / \mathrm{kW}_{\text {rated }}$ & 0.08145 & 0.08145 & 0.08145 & 0.08145 \\
\hline \hline$F_{1}$ & $\mathrm{~L} / \mathrm{h} / \mathrm{kW}$ & 0.246 & 0.246 & 0.246 & 0.246 \\
\hline$c_{B T}$ & - & 0.927 & 0.267 & 0.369 & 0.355 \\
\hline \hline$G_{L F}$ & $\%$ & 30 & 30 & 30 & 30 \\
\hline Lifetime & hours & 15,000 & 15,000 & 15,000 & 15,000 \\
\hline
\end{tabular}

Table A.17: Converter parameters used in the simulation.

\begin{tabular}{llllll}
\hline \multirow{2}{*}{ Parameter } & Unit & \multicolumn{4}{c}{ Values per technology type } \\
\cline { 3 - 6 } & & 1 & 2 & 3 & 4 \\
\hline Manufacturer & - & Generic & Generic & Generic & Generic \\
Rated capacity & $\mathrm{kW}$ & 200 & 250 & 270 & 300 \\
Inverter \% & $\%$ & 95 & 95 & 95 & 95 \\
Relative capacity & $\%$ & 100 & 100 & 100 & 100 \\
Rectifier \% & $\%$ & 90 & 90 & 90 & 90 \\
Lifetime & years & 20 & 20 & 20 & 20 \\
\hline
\end{tabular}

${ }^{1}$ Relative capacity of the rectifier in relation to the inverter. 